\title{
Obtaining the correct sea surface temperature: bias correction of regional climate model data for the Mediterranean Sea
}

\author{
Diego Macias $^{1} \cdot$ Elisa Garcia-Gorriz $^{1} \cdot$ Alessandro Dosio $^{1} \cdot$ Adolf $^{-S_{t i p s}}{ }^{1}$. \\ Klaus Keuler ${ }^{2}$
}

Received: 13 August 2015 / Accepted: 16 February 2016 / Published online: 29 February 2016

(C) The Author(s) 2016. This article is published with open access at Springerlink.com

\begin{abstract}
Here, the COSMO Climate Limited-area Modelling (CCLM) regional climate model (RCM) is used as external forcing for a Mediterranean basin-scale ocean model based on the general estuarine transport model (GETM). CCLM is forced by different global climate models (GCMs) (MPI and EcEarth) and by the ERA-interim (ERAin) reanalysis. Sea surface temperatures (SST) simulated by the different runs of the ocean model are compared with satellite measurements. As a substantial cold bias in simulated SST is found, a simple bias-correction methodology is applied to the RCM atmospheric variables, namely (1) air temperature (which is usually underestimated for the region by RCMs runs), (2) cloud cover (typically overestimated) and (3) wind intensity (as zonal wind intensity is usually overestimated). The performed analysis identifies wind velocity as the most important variable to correct in order to satisfactorily obtain Mediterranean SST. For many
\end{abstract}

This paper is a contribution to the special issue on MedCORDEX, an international coordinated initiative dedicated to the multi-component regional climate modelling (atmosphere, ocean, land surface, river) of the Mediterranean under the umbrella of HyMeX, CORDEX, and Med-CLIVAR and coordinated by Samuel Somot, Paolo Ruti, Erika Coppola, Gianmaria Sannino, Bodo Ahrens, and Gabriel Jordà.

Electronic supplementary material The online version of this article (doi:10.1007/s00382-016-3049-z) contains supplementary material, which is available to authorized users.

Diego Macias

diego.macias-moy@jrc.ec.europa.eu

1 European Commission, Joint Research Centre, Institute for Environment and Sustainability, 21027 Ispra, Italy

2 Brandenburg University of Technology (BTU), Chair of Environmental Meteorology, Burger Chaussee 2, Haus 4/3, D-03044 Cottbus, Germany of the RCM realizations significant improvement in the simulated SST are only achieved when wind intensity values were bias-corrected towards observed values. Air temperature and cloud cover had a more marginal importance in reducing the SST bias observed in RCM-forced runs of the ocean model. By comparing the ERAin-driven run and the GCMs driven runs, our analyses suggest that the main source of observed bias is related with the GCMs being used as lateral boundary condition for the RCM realizations. However, a relative simple bias-correction methodology is sufficient to reduce a large part of the induced bias in SST and to improve the vertical water stratification characteristics within the Mediterranean basin that will allow to analyze current and future biogeochemical conditions of the studied basin.

Keywords Ocean modelling $\cdot$ Mediterranean Sea $\cdot$ Sea surface temperature $\cdot$ Bias correction

\section{Introduction}

Coupled numerical models that include both atmosphere and ocean components are fundamental tools to study the present condition, past evolution and future scenarios of marine systems. These tools have been used for quite a long time now and different solutions have been adopted to couple the different sub-models.

The most complete and accurate way of performing this type of simulations is by using fully coupled (twoways) atmospheric and oceanic models. In this case the whole range of interactions from the atmosphere to the surface ocean and from the ocean to the atmosphere is considered (e.g., Dubois et al. 2012) despite of larger computing time. 
However, the most common type of atmosphere-ocean models are the forced models. In such models atmospheric variables (either from models or from reanalysis data) are used to force the ocean model at the surface so they provide a good description of the influence of atmospheric processes on ocean variability. With this structure, however, the feedbacks and interactions between ocean surface characteristics and the atmosphere are not considered (SanchezGomez et al. 2011).

A common problem to most atmospheric models is the presence of biases in some of the simulated atmospheric variables (Ehret et al. 2012). If atmospheric conditions are not properly represented, the induced oceanic characteristics in the ocean model will be not correct. For example, forcing the same ocean model of the Mediterranean Sea with atmospheric variables from one of the latest stateof-the art regional climate models (within the Climate Change and Impact Research (CIRCE) initiative) and with reanalysis data (Adani et al. 2011) has indicated a significant cold bias in the simulated sea surface temperature (SST) for present-day conditions of approximately $2.5^{\circ} \mathrm{C}$ (Dell'Aquila et al. 2012). Also Somot et al. (2006) reported a generalized cold bias of $\sim{ }^{\circ} \mathrm{C}$ in mean simulated SST for present-day conditions when forcing an ocean model with atmospheric variables derived from a Regional Climate Model (RCM). A way to try to overcome this problem is to perform bias correction of the atmospheric variables (e.g., Dosio et al. 2012) before using them to force the ocean model (Sanchez-Gomez et al. 2011). This is done by comparing modeled variables with data (or reanalysis products) and applying a transfer function to eliminate (or reduce) the bias by matching the cumulative distribution functions of modeled and observed data (e.g., Wood et al. 2004; Li et al. 2010; Heinrich and Gobiet 2011).

A proper simulation of the present day surface characteristics of the oceanic system is crucial to analyze the biogeochemical conditions of the studied basin. Atmosphere-ocean interactions determine the level of vertical stratification and stability, the strength and position of currents and fronts and the mesoscale surface activity. All these physical characteristics determine the level and distribution of biological production in the ocean by controlling mixing and advection processes (Vichi et al. 2003; Steinacher et al. 2010). If by bias correcting atmospheric variables we are able to simulate the present day characteristics of the surface ocean satisfactorily, this type of forced systems could, potentially, be used to make scenario projections into the likely future conditions (physical and biological) of the considered marine system (e.g., Somot et al. 2006; Adloff et al. 2015). Although bias-correcting atmospheric model variables before using it to force ocean models is quite a common practice (e.g., Pettenuzzo et al. 2010) the effect of this procedure on the final results and the exact details on how this is done are not usually provided to the end users (Ehret et al. 2012).

In the present study an ocean model based on the general estuarine transport model (GETM) for the whole Mediterranean Sea is used. When forced with atmospheric variables coming from reanalysis data (ERA-Interim, Dee et al. 2011), this particular ocean model has been shown to correctly simulate the surface characteristics (both physical and biological) of the Mediterranean basin during the past few decades (Macias et al. 2013, 2014a, b). As a consequence even if reanalysis datasets may present considerable deviations from the 'true' weather (Maraun et al. 2010), in this study the ERA-Interim (ERAin) reanalysis is considered as 'observations' for the purposes of the bias-correction analysis presented below.

This same ocean model with the same exact configuration is also forced at the surface with the atmospheric variables provided by an RCM, namely the Cosmo Climate Limited-area Model (hereinafter CCLM). This RCM has been shown to provide quite accurate conditions for the European and Mediterranean region when using reanalysis data as boundary conditions and to improve water and heat fluxes over this basin with respect to the raw reanalysis products (Sanchez-Gomez et al. 2011). Three realizations of this RCM are considered here, both using the ERAin data as boundary conditions and using the simulations from two global circulation models (GCM) as lateral boundary conditions.

Simulated SST values from the different ocean model runs are compared with satellite data to identify the presence of bias. SST biases are assessed at annual and seasonal scales throughout the entire simulation period (1989-2005). Furthermore, the importance of each of the atmospheric variables for the simulated SST by the ocean model is assessed. Henceforth, the effects of bias-adjusting the three main atmospheric variables influencing SST (air temperature, cloud cover and wind) are evaluated individually and for each one of the RCM realizations. The comparison of the partially-corrected runs indicates for each RCM realization which variable(s) are most important to correct and, hence, help to direct future efforts in Mediterranean climate modelling.

Description of the used models (oceanic and atmospheric), of the bias correction techniques and of the used satellite data are provided in Sect. 2. Main results are presented in Sect. 3 while discussion could be found in Sect. 4.

\section{Materials and methods}

All simulations were performed using the same regional ocean model for the entire Mediterranean Sea (Fig. 1) forced at the surface with different atmospheric conditions 
Fig. 1 Ocean model domain with main bathymetric lines. Included rivers are shown with blue stars in the coast

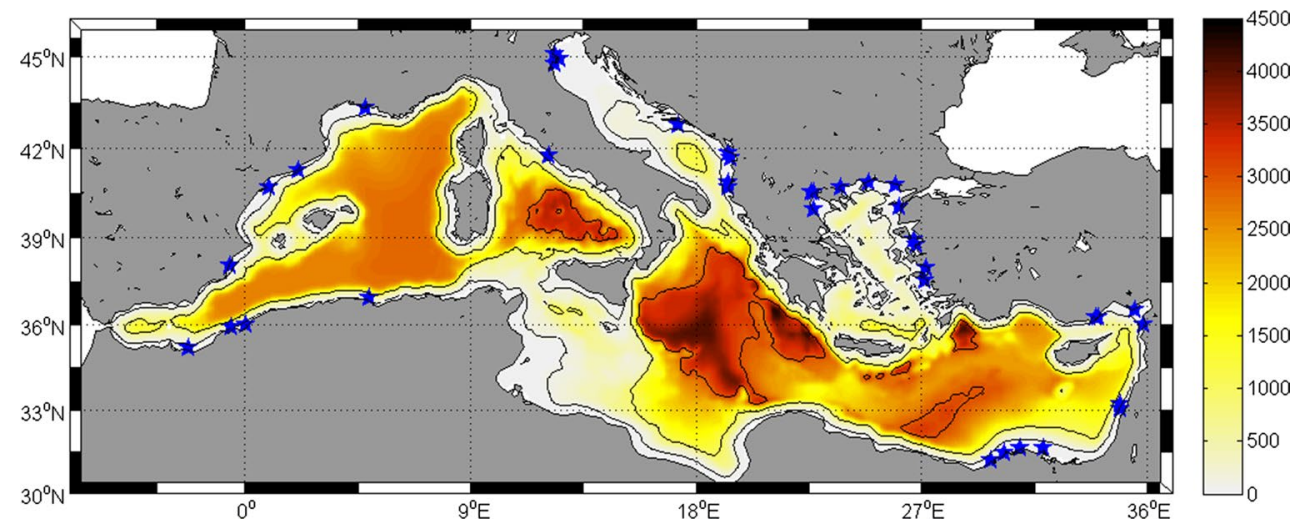

derived either from reanalysis data or from the RCM. We will describe first the ocean model configuration in Sect. 2.1 and the different atmospheric forcings in Sect. 2.2. The techniques for bias-correcting the atmospheric variables are described in Sect. 2.3. The remote sensing SST data used to evaluate model performance is described in Sect. 2.4.

\subsection{Mediterranean ocean model}

The 3-D General Estuarine Transport Model (GETM) was used to simulate the hydrodynamics in the Mediterranean Sea. GETM solves the three-dimensional hydrostatic equations of motion applying the Boussinesq approximation and the eddy viscosity assumption (Burchard and Bolding 2002). A detailed description of the GETM equations can be found in Stips et al. (2004) and at http:// www.getm.eu.

The configuration of the Mediterranean Sea (Fig. 1) has a horizontal resolution of $5^{\prime} \times 5^{\prime}$ and includes 25 vertical layers. ETOPO1 (http://www.ngdc.noaa.gov/mgg/ global/) was used to build the bathymetric grid by averaging depth levels to the corresponding horizontal resolution of the model grid. The initial conditions are the salinity and temperature climatologies from the Mediterranean Data Archaeology and Rescue-MEDAR/MEDATLAS database (http://www.ifremer.fr/medar/). The ocean model is run during 5 years repeating the atmospheric forcing (spin-up) corresponding to 1989 in order to avoid strong trends.

Boundary conditions at the western entrance of the Strait of Gibraltar were also computed from the same MEDAR/ MEDATLAS dataset imposing monthly climatological vertically-explicit values of temperature and salinity. No horizontal currents were imposed at the open boundary. With this boundary configuration the circulation through the Strait is established by the internally adjusted baroclinic balance provoked mainly by the deep-water formation within the basin (e.g., Sannino et al. 2015). Although the magnitude of the heat transport and horizontal velocities in Gibraltar are in general agreement with observations (Llasses et al. this issue) both the water transport and the circulation pattern within the Alboran Sea are typically weaker than expected (see discussion below). The present model set-up includes 37 rivers discharging along the Mediterranean coast. The corresponding river discharges were derived from the Global River Data Center (GRDC, Germany) database. Data gaps in fluxes from rivers were filled with climatological values.

The GETM configuration for the Mediterranean Sea is forced at surface every $6 \mathrm{~h}$ by the following atmospheric variables; wind velocity at 10 meters (U10 and V10), air temperature at $2 \mathrm{~m} \mathrm{(t2),} \mathrm{dew} \mathrm{point} \mathrm{temperature}(\mathrm{d} 2)$, cloud cover (tcc) and sea level pressure (SLP). The different sources for this atmospheric forcing are described in Sect. 2.2. All atmospheric variables are spatially and temporally interpolated to the model grid and time step.

The heat and momentum ocean fluxes are internally calculated in GETM based on the modelled atmospheric variables using appropriate bulk flux algorithms. The turbulent bulk fluxes of heat and momentum are calculated using the algorithms provided by Kondo (1975). In this calculation the sea surface temperature from the model is used to ensure proper heat flux feedback from the changing sea surface temperature. The net heat flux is calculated as the sum of net shortwave radiation, net longwave radiation, latent heat flux and sensible heat flux. The net heat flux is calculated as positive going into the sea and negative when leaving the sea.

Net shortwave radiation is calculated following Reed (1977), which is based on measurements from Paulson and Simpson 1977) and applying the albedo algorithm from (Payne 1972). The net longwave radiation is calculated according to Josey (2003), as they provided an algorithm version specifically designed for the Mediterranean Sea. Precipitation is taken directly from the atmosphere model, whereas evaporation or condensation are calculated using a bulk algorithm consistent with the latent heat calculation. 
Table 1 List of atmospheric forcing datasets used to force the ocean model

\begin{tabular}{llll}
\hline $\begin{array}{l}\text { Name of forcing } \\
\text { dataset }\end{array}$ & Used RCM & $\begin{array}{l}\text { Boundary } \\
\text { conditions }\end{array}$ & $\begin{array}{l}\text { Type of } \\
\text { simulation }\end{array}$ \\
\hline ERAin & - & ERAin & \\
CCLM-ERAin & CCLM & ERAin & Evaluation \\
CCLM-MPI & CCLM & MPI & Historical \\
CCLM-EC & CCLM & EcEarth & Historical \\
\hline
\end{tabular}

\subsection{Atmospheric forcing to the ocean model}

\subsubsection{Reanalysis data}

The European Center for Medium Range Weather Forecast (ECMWF) datasets are used as atmospheric forcing to the ocean model to create a baseline simulation. ERAin data (Uppala et al. 2008; Dee et al. 2011) from 1989 to 2005 have been selected due to their improved temporal and spatial coverage with respect to other reanalysis products. This combination of model/forcing has been shown to provide consistent simulations of SST in the Mediterranean Sea for a relatively long period (1959-2012) (Macias et al. 2013).

\subsubsection{Regional climate model}

In this study, we use the three-dimensional non-hydrostatic regional climate model COSMO-CLM (CCLM) in the same configuration described in Jacob et al. (2014), Vautard et al. (2013) and Kotlarski et al. (2014) for the EUROCORDEX domain. CCLM has been successfully applied to other CORDEX regions, such as Africa by Panitz et al. (2014), Dosio et al. (2015) and Dosio and Panitz (2015).

Briefly, numerical integration is performed on an Arakawa-C grid with a Runge-Kutta scheme, with a time splitting method by Wicker and Skamarock (2002). A vertical hybrid coordinate system with 40 levels is used. The main physical parameterizations include: the radiative transfer scheme by Ritter and Geleyn (1992); the Tiedtke parameterization of convection (Tiedtke 1989) being modified by D. Mironow (German Weather Service); a turbulence scheme (Raschendorfer 2001; Mironov and Raschendorfer 2001) based on prognostic turbulent kinetic energy closure at level 2.5 according to Mellor and Yamada (1982); a one-moment cloud microphysics scheme, a reduced version of the parameterization of Seifert and Beheng (2001); a multi layer soil model (Schrodin and Heise 2002; Heise et al. 2003); subgrid scale orography processes (Schulz 2008; Lott and Miller 1997). A thorough description of the dynamics, numerics and physical parametrizations can be found in the model documentation (e.g., Doms 2011).
The numerical domain, common to all groups participating to the EURO-CORDEX initiative, covers the entire European Continent and the Mediterranean Sea at $0.11^{\circ}$ horizontal resolution (see Fig. 1 of Kotlarski et al. 2014). The model grid consists of 450 points from West to East and 438 points from South to North, including a sponge zone of 12 grid points at each side, where the Davies boundary relaxation scheme is used (Davies 1976, 1983).

Two sets of simulations have been run: first an 'evaluation run' driven by the ERAin reanalysis, providing the atmospheric lateral boundary conditions, sea surface temperatures and sea ice cover over ocean surfaces, for the period 1989-2008.

Second, 'historical' simulations have been run by downscaling the results of two GCMs from the CMIP5 climate projections, namely: the Max Plank Institute MPI-ESMLR, and EC-Earth, i.e., the Earth System Model of the ECEarth Consortium (http://ecearth.knmi.nl/). These historical runs, forced by observed natural and anthropogenic atmospheric composition, cover the period from 1950 until 2005 and are named CCLM-MPI and CCLM-EC throughout the text (see Table 1).

\subsection{Bias correction techniques}

The bias correction technique applied in this work is based on a simplified version of the one proposed by Piani et al. (2010) and applied to climatic change simulations for Europe by Dosio and Paruolo (2011) and by Dosio et al. (2012). The basic principle is to find a transfer function (TF) that allows matching the cumulative distribution functions (CDFs) of modeled and observed data. In the present application a linear TF based in Piani et al. (2010) is used as:

$X_{i t}^{c}=a+b X_{i t}^{m}$

where $X_{i t}^{c}$ is the corrected variable, $X_{i t}^{m}$ is the model uncorrected variable and ' $a$ ' and ' $b$ ' are the linear fitting coefficients found when comparing the model uncorrected variable with the observed variable $X_{i t}^{o}$ using the least square error method. In this analysis 'observed' variables are the ones provided by the reanalysis dataset (ERAin) and the 'model' variables come from the different realizations of the RCM as described in Sect. 2.2 above. With this methodology the CDFs of 'observed' and 'corrected' model variables are equivalent while the internal variability in the 'uncorrected' model variable is retained. Contrary to previous works, we use spatially-averaged values of the 'observed' and 'model' variables over the entire Mediterranean Sea basin, so no spatially explicit correction is applied.

From the different atmospheric variables used to force the ocean model (see Sect. 2.1 above) there are three that 
are fundamental to determine SST; air temperature, cloud cover and wind intensity. The gradient between the air temperature (t2) and the SST determines the radiative (long wave), latent and sensible heat flux into or out the sea. Total cloud cover (tcc) influences the long-wave radiation leaving the ocean and the short-wave radiation reaching the sea surface during daytime. Finally, wind intensity (U10 and V10) largely determines the surface water mixing influencing sensible and latent heat fluxes. Therefore, to get the correct SST it is very important that those variables are as accurate as possible.

The 'transfer function' (Eq. 1) has been applied to both t2 and tcc (see results) but not for wind intensity. It was not possible to determine the functional relationship linking observed and modeled U10 and V10, so to bias correct wind intensity a much simpler approach was used. In this case, the mean absolute wind intensities in meridional and zonal directions were adjusted to match the ones provided by the reanalysis data (see details in results below).

\subsection{Satellite data}

In the present study, we employed the $4 \mathrm{~km}$ Advanced Very High-Resolution Radiometer (AVHRR) Pathfinder Version 5 SST dataset. AVHRR Oceans Pathfinder SST data were obtained from the Physical Oceanography Distributed Active Archive Center (PO.DAAC) at the NASA Jet Propulsion Laboratory, Pasadena, CA (http://podaac.jpl. nasa.gov, accessed 2015 March 25th). This dataset represents a reanalysis of historical AVHRR data that have been improved through extensive calibration and validation and using any other available information to yield a consistent research-quality time series for global climate studies. This SST time series represents the longest continuous set of physical measurements for the global ocean obtained from space and has been shown to agree quite well with in situ temperature data in the Mediterranean Sea (Nykjaer 2009).

\section{Results}

\subsection{Non-corrected (control) runs}

As a first test we run a set of simulations forcing our Mediterranean ocean model with the atmospheric variables provided by the reanalysis data (ERAin) and by the different realizations of CCLM using the diverse boundary conditions (ERAin, MPI and EC-Earth) as described in the sections (see also Table 1).

In Fig. 2a the mean annual SST values for the entire Mediterranean Sea are shown for the Pathfinder data and for the different model runs. Even if all runs are initialized with the same initial conditions (see Methods) the first data point of Fig. 2a time series are different for each model run as it represents the mean SST throughout the first simulated year (i.e., 1989). As expected, it could be seen that the ERAin forced run and the CCLM-ERAin forced run are the two simulations where annual mean SST are closest to observed satellite values and displaying the same interannual variability. ERAin run is around $0.13{ }^{\circ} \mathrm{C}$ warmer than observations while CCLM-ERAin results are almost $0.8{ }^{\circ} \mathrm{C}$ colder than satellite (Table 2). In both simulations, however, the mean SST is not significantly different to the mean satellite value ( $t$ student test, $99 \%$ confidence) over the considered period. Moreover, the annual time series of SST in these two simulations remain fairly close to the satellite nominal root mean square error range assumed to be $\pm 0.5{ }^{\circ} \mathrm{C}$ (Marullo et al. 2007) for the Mediterranean Sea. Quite remarkable is also the convergence of the ERAin forced run with the satellite data towards the end of the simulation period.

On the contrary, the two simulations performed using the GCMs as boundary conditions for CCLM show significantly lower temperatures during the simulation period (Fig. 2a) with mean SST being 1.28 and $1.68{ }^{\circ} \mathrm{C}$ colder for the CCLM-MPI and CCLM-EC runs respectively (Table 2). In both cases the differences are significant at the $99 \%$ confidence level ( $t$ student test) and the simulated SST time series are well below the error interval of the satellite data (Fig. 2a). The lack of concordance in the interannual variations of SST obtained with the GCMs derived runs and the satellite data is expected because historical model simulations do not follow the real chronology of past atmospheric state.

The seasonal climatological SST cycles from satellite and from the different model runs are presented in Fig. $2 b$. Here it is clear that the ERAin forced run shows a quasiconstant warm bias of $\sim 0.3-0.5{ }^{\circ} \mathrm{C}$ during the first half of the year and that it decreases considerably during late summer and fall, being closer to satellite observations. A common pattern is also visible in the different RCM-forced runs with winter values closer to observations and larger (cold) bias during summer months. CCLM-ERAin forced run is the closest to the satellite data with smaller bias in winter $\left(\sim-0.16{ }^{\circ} \mathrm{C}\right)$ but a larger bias from June to December $\left(\sim-1{ }^{\circ} \mathrm{C}\right)$. CCLM-MPI forced simulation shows a similar cold bias during winter $\left(\sim-0.2^{\circ} \mathrm{C}\right)$ but a much larger bias during summer/fall $\left(\sim-2.3{ }^{\circ} \mathrm{C}\right)$. Finally, CCLM-EC forced run shows the largest bias of all with a mean winter deviation of $\sim-0.51{ }^{\circ} \mathrm{C}$ and summer/fall bias of $\sim-2.5^{\circ} \mathrm{C}$.

The scatter plot of monthly mean SST values (Fig. 2c) further stresses the fact that the largest differences between the RCM-forced runs and the satellite values appear in the upper range of temperatures (i.e., during summer months). Winter values (colder SST), on the other hand, show smaller deviation from the 1:1 line (Fig. 2b). 

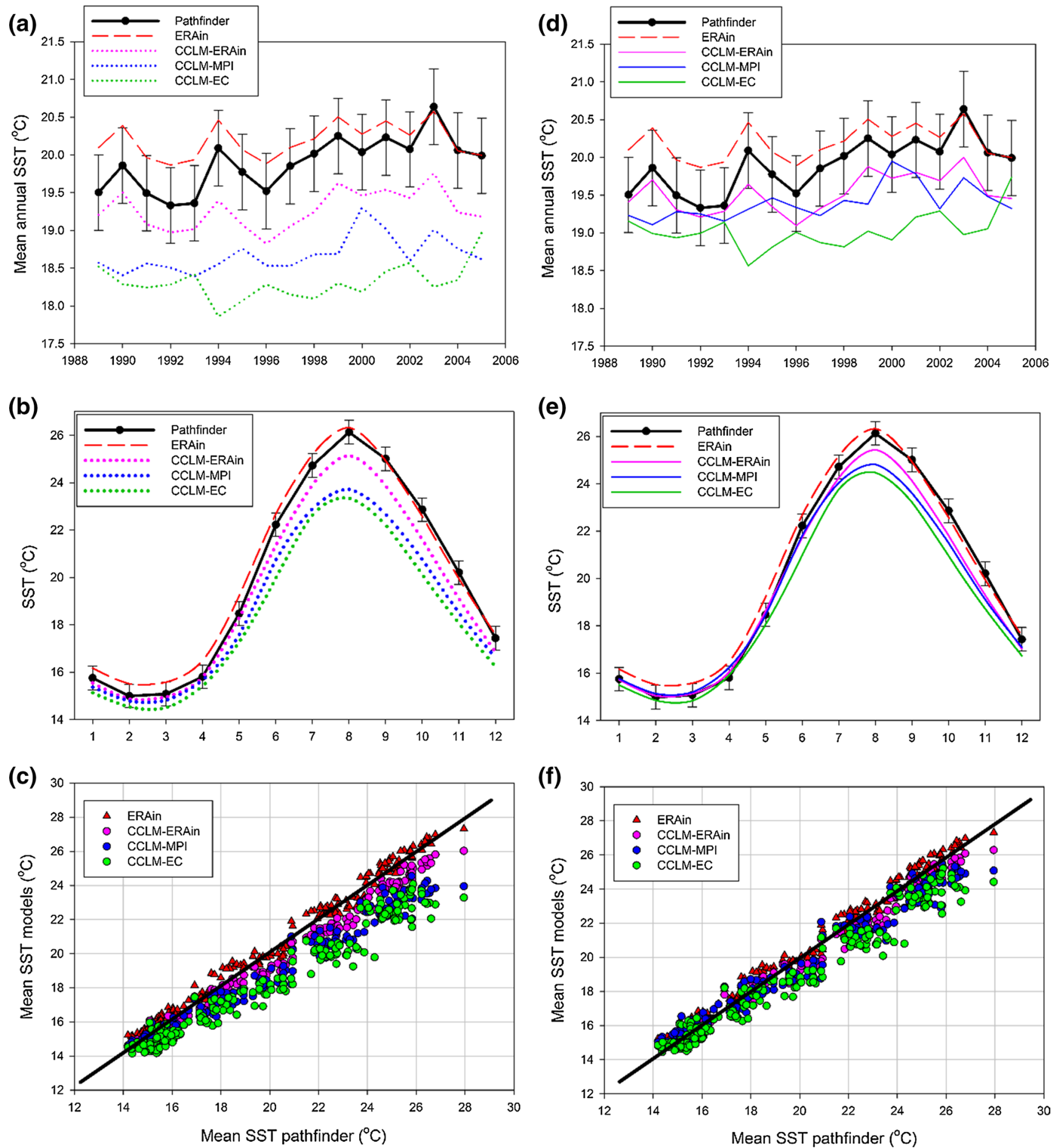

Fig. 2 a Mean annual SST time series from satellite data (black) and from the different non corrected model runs. The error range associated with satellite measurements is also shown. b Seasonal SST cycles from the satellite data and from the different uncorrected

(f)

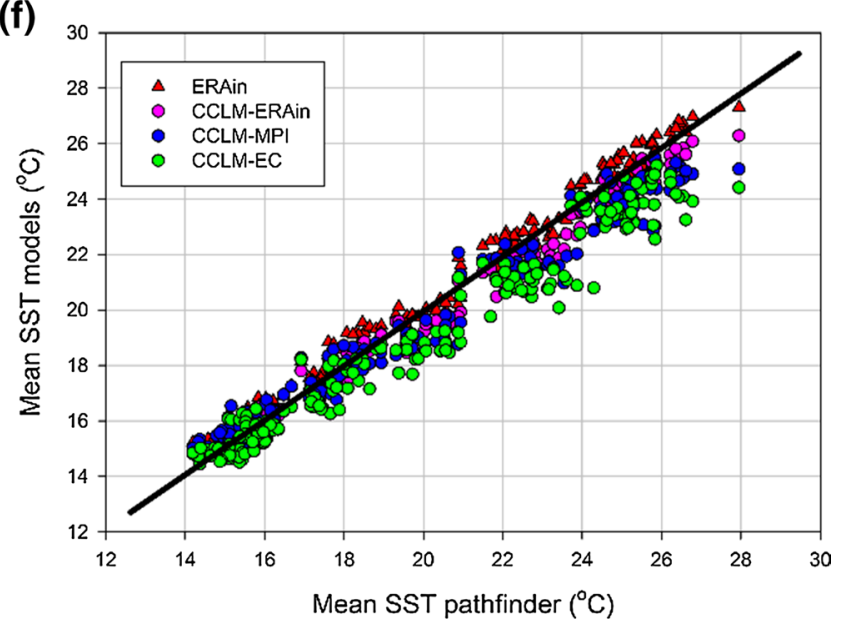

model runs. c Scatter plot of monthly mean SST values from satellite versus monthly mean SST from the uncorrected model runs. The 1:1 ratio is shown for reference as a black bold line. Panels $\mathbf{d}, \mathbf{e}$ and $\mathbf{f}$ are the corresponding for the bias-adjusted runs

\subsection{Bias correction of atmospheric variables}

shows very good agreement with satellite values throughout the entire temperature range (dark red triangles in Fig. 2c).

The disagreement between simulated and observed SST when forcing the ocean model with CCLM data raised 
Table 2 Mean SST observed or simulated with the different forcings to the oceanic models with and without bias correction

\begin{tabular}{lll}
\hline & $\begin{array}{l}\mathrm{SST}\left({ }^{\circ} \mathrm{C}\right)(\Delta \mathrm{T}) \\
\text { uncorrected }\end{array}$ & $\begin{array}{l}\mathrm{SST}\left({ }^{\circ} \mathrm{C}\right)(\Delta \mathrm{T}) \\
\text { bias-corrected }\end{array}$ \\
\hline Pathfinder & 19.88 & \\
ERAin & $20.10\left(+0.31^{\circ}\right)^{\mathrm{b}}$ & \\
CCLM-ERAin & $19.27\left(-0.61^{\circ}\right)^{\mathrm{b}}$ & $19.52\left(-0.36^{\circ}\right)^{\mathrm{b}}$ \\
CCLM-MPI & $18.67\left(-1.20^{\circ}\right)^{\mathrm{a}}$ & $19.39\left(-0.48^{\circ}\right)^{\mathrm{b}}$ \\
CCLM-EC & $18.29\left(-1.58^{\circ}\right)^{\mathrm{a}}$ & $19.01\left(-0.86^{\circ}\right)^{\mathrm{b}}$ \\
\hline
\end{tabular}

Pathfinder SST is considered as the baseline

a Values statistically different at $99 \%$ confidence

b Values not statistically different at $99 \%$ confidence ( $t$ student test)

the necessity of performing a bias-correction in order to improve the simulation of present-day surface temperature in the basin. As mentioned in the Sect. 2, we consider the three variables that have major importance in determining the SST computed by the ocean model; air temperature (t2), cloud cover (tcc) and wind speed (zonal and meridional components, U10 and V10).

The two first atmospheric variables (t2 and tcc) are bias corrected using the method described in the previous section (Eq. 1). For $\mathrm{t} 2$, the scatter plot of original values from the RCM realizations versus the ERAin data (Fig. 3a) shows that significant deviation are mainly present in the higher temperature region, where simulated $\mathrm{t} 2$ are lower than reanalysis values. This is especially appreciable in the CCLM realizations using the two GCMs as boundary conditions (with goodness-of-fit coefficients (GoF) of 0.7), being less evident in the CCLM-ERAin realization

(a)

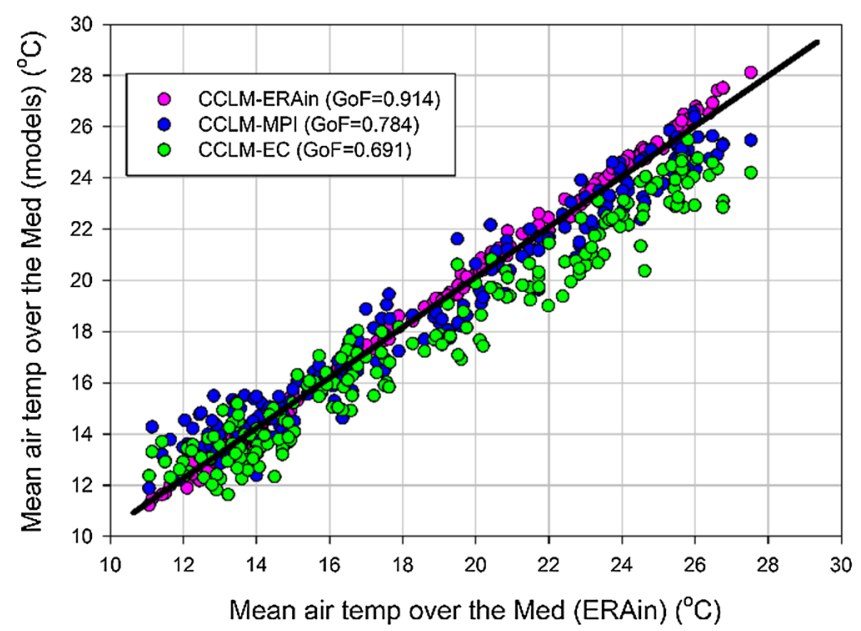

Fig. 3 a Monthly mean air temperature (t2) over the Mediterranean basin in the ERAin dataset versus monthly mean air temperature over the Mediterranean in the different RCM realizations. b Same as a but
Table 3 Mean $\mathrm{t} 2$ values before and after applying the bias-correction transfer function

\begin{tabular}{ll}
\hline Realization & Mean value (before/after) bias correction \\
\hline CCLM-ERAin & $19.0 / 18.73{ }^{\circ} \mathrm{C}$ \\
CCLM-MPI & $18.77 / 18.73{ }^{\circ} \mathrm{C}$ \\
CCLM-EC & $17.9 / 18.73{ }^{\circ} \mathrm{C}$ \\
\hline
\end{tabular}

(GoF 0.9). After applying the bias correction it could be clearly seen (Fig. $3 b$ ) that model and reanalysis $t 2$ values agree better throughout the entire range, with improved GoF coefficients for all three CCLM realizations. The mean values of $\mathrm{t} 2$ for the uncorrected and corrected realizations (Table 3) clearly indicate that significant correction is applied for CCLM-EC (average difference between uncorrected/corrected $\sim 0.83{ }^{\circ} \mathrm{C}$ ) while the other two realizations show much smaller differences $\left(\sim 0.27\right.$ and $0.04{ }^{\circ} \mathrm{C}$ for CCLM-ERAin and CCLM-MPI, respectively). Analyzing the effect of the $\mathrm{t} 2$ bias correction by season (see Table 4 ) it could be seen that the different CCLM realization seems to be doing a better job during the transition periods (i.e., spring and fall) and worse during both winter and summer, with lower GoF scores. The effect of bias-correction is quite evident in all seasons and for all CCLM realizations although for winter, CCLM-MPI and CCLM-EC still have a quite low GoF after the correction.

The bias correction for tcc has been performed separating the different times of the day when data is available (midnight, 6 a.m., noon and 6 p.m.) as the effect of clouds on SST is different during the night (when clouds mostly confine long-wave radiation leaving the ocean) and during

(b)

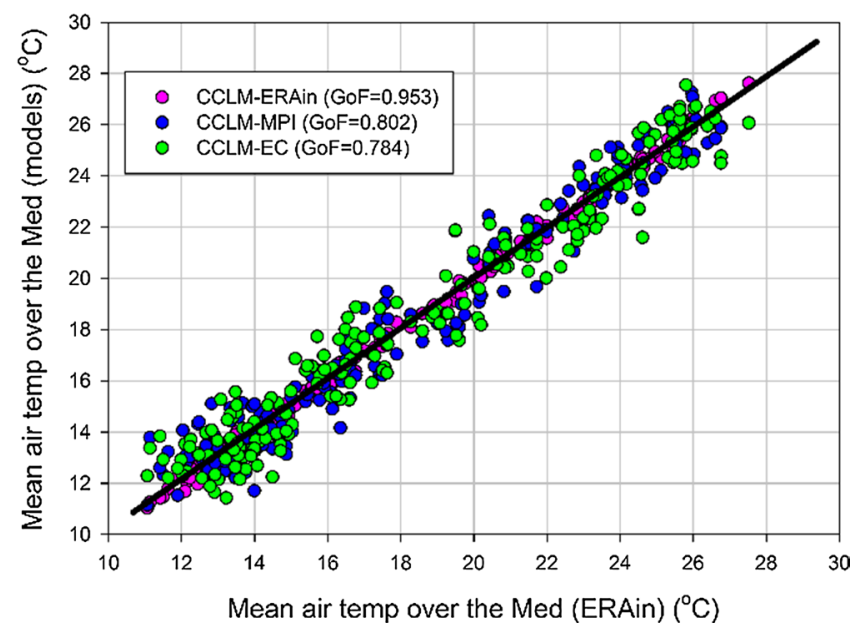

after the bias correction is applied. The goodness-of-fit (GoF) computed by using the normalized root mean square error is indicated beside each time series 
the day (when clouds principally prevent the short-wave solar radiation for heating the sea). For all the different times, the uncorrected modeled tcc (Fig. 4, left column) are larger than the reanalysis values with very low GoF coefficients. When the bias correction is applied (Fig. 4, right column) this overestimation disappears and the scatter is better aligned along the 1:1 ratio, with much improved GoF coefficients for all realizations. No significant differences between the different RCM realizations could be observed for this variable.

The last atmospheric variable to correct (wind) is more difficult to analyze as there are no statistically significant correlations between absolute wind intensities in the RCM realizations and in the reanalysis data (not shown), and as a result it was not possible to find a suitable TF for the correction. Thus, a simpler approach is used by calculating the ratio between mean values of each component in each dataset (see Table 5). This ratio is then applied to the different winds components in each model so their mean values agree with the ERAin mean figure. The results of this correction are shown in Fig. 5. On the left column the uncorrected U10 and V10 time series are shown while the corrected values are presented in the right column. As can be seen, after the bias correction wind intensity values from the different model realizations are closer to the reanalysis data and their dispersion around the mean is more similar with a sensible improvement of the GoF coefficients. A spatial comparison of the uncorrected and corrected wind fields (Figs. S5 and S6) did not reveal significant changes on winds spatial distribution and direction.

\subsection{Consequences of the bias correction on ocean surface properties}

After the atmospheric variables have been bias-corrected, the ocean model is re-run. The time series of annual mean SST values obtained in this new set of simulations are shown in Fig. 2d. Comparing this with Fig. 2a, it is evident that for all RCM realizations the mean simulated SST are closer to the satellite observed values. Also, the statistical analysis shown in Table 2 reveals that the mean simulated SST using the bias-corrected atmospheric values are not statistically different from the mean satellite value. All the mean annual SST time series are within the root mean square error of satellite data except for CCLM-EC forced
Fig. 4 Left column Monthly mean cloud cover (tcc) over the Mediterranean basin in the ERAin dataset versus monthly mean cloud cover over the Mediterranean in the different RCM realizations and for the different times of the day. Right column Same as above after the bias correction. The goodness-of-fit (GoF) computed by using the normalized root mean square error is indicated beside each time series

run and some scattered years in the CCLM-MPI forced run (Fig. 2d). SST seasonal cycles obtained in these simulations (Fig. 2e) also show a net improvement when compared with the uncorrected runs (Fig. 2b). Especially the strong cold bias during summer/autumn is reduced from $\sim 2.3$ to $\sim-1{ }^{\circ} \mathrm{C}$ for CCLM-MPI and from $\sim-2.5$ to $\sim-1.4{ }^{\circ} \mathrm{C}$ for CCLM-EC. This same pattern is shown by the scatter plot of simulated monthly mean SST versus satellite data (Fig. 2f) as the clear underestimation of the warmer SST values shown before (Fig. 2c) is strongly reduced, although some small deviations are still present at the warmest range of temperatures.

It is interesting to compare the climatologic SST distribution from Pathfinder (Fig. 6a) with the corresponding fields from the different simulations (uncorrected and corrected). For the ERAin driven simulation (Fig. 6b) the mean difference between simulated and observed SST is $+0.31{ }^{\circ} \mathrm{C}$ with anomalies values inside the satellite error intervals in around $57 \%$ of the basin. Larger differences are observed along the coastal regions of the Western Mediterranean and through the central basin. Eastern Mediterranean SST values are well simulated in this model run.

For the simulations forced with atmospheric data from RCM realizations, the best fit with climatologic SST fields is obtained with the CCLM-ERAin driven simulation (Fig. 6c) where the mean difference is $-0.55{ }^{\circ} \mathrm{C}$ and differences are outside the error intervals in around $51 \%$ of the basin. In this case, only the eastern Mediterranean basin and some coastal zones within the western basin shows SST differences within the error interval while the majority of the western basin is colder than observed. When the bias-correction is applied, the mean deviation for CCLMERAin driven simulation decreases to $-0.34{ }^{\circ} \mathrm{C}$ and the area where SST anomalies are within the threshold is increased to $73 \%$ of the basin (Fig. 6f). In this spatial map it could be seen that the main improvement with respect to the uncorrected simulation happens in the coastal regions of the western and northeastern Mediterranean with only
Table 4 Goodness-of-fit (GoF) computed by using the normalized root mean square error between monthly mean $\mathrm{t} 2$ from ERAin and the different CCLM realizations (seasonal data)

\begin{tabular}{lllll}
\hline Realization & Winter (D-J-F) & Spring (M-A-M) & Summer (J-J-A) & Fall (S-O-N) \\
\hline CCLM-ERAin & $0.871 / 0.946$ & $0.958 / 0.994$ & $0.886 / 0.979$ & $0.945 / 0.987$ \\
CCLM-MPI & $-0.38 /-0.03$ & $0.788 / 0.798$ & $0.528 / 0.661$ & $0.740 / 0.784$ \\
CCLM-EC & $-0.012 / 0.129$ & $0.431 / 0.652$ & $-1.1 / 0.48$ & $0.614 / 0.698$ \\
\hline
\end{tabular}

First value corresponds to the uncorrected realization and the second value to the bias-corrected one 

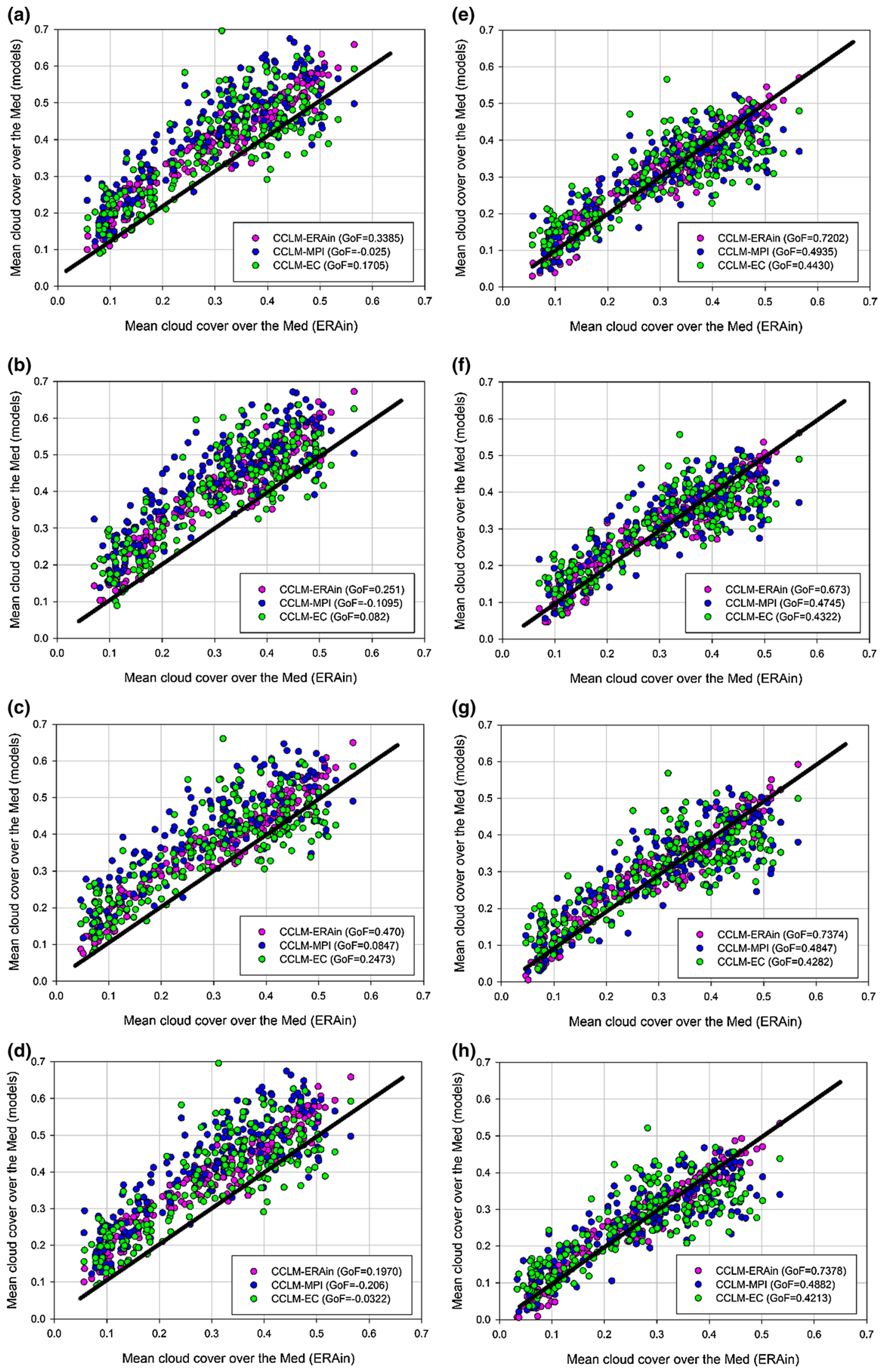
Table 5 Mean absolute values of both wind components in each dataset/model

\begin{tabular}{llll}
\hline Wind component & Forcing model/dataset & Absolute mean value $(\mathrm{m} / \mathrm{s})$ & Ratio (ERAin value/model value) \\
\hline U10 & ERAin & 1.17 & - \\
& CCLM-ERAin & 1.3 & 0.9 \\
& CCLM-MPI & 1.97 & 0.59 \\
& CCLM-EC & 1.41 & 0.82 \\
V10 & ERAin & 1.28 & - \\
& CCLM-ERAin & 1.24 & 1.03 \\
& CCLM-MPI & 1.06 & 1.2 \\
& CCLM-EC & 1.16 & 1.1 \\
\hline
\end{tabular}

The ratio in the right column is the value used to bias-correct model values
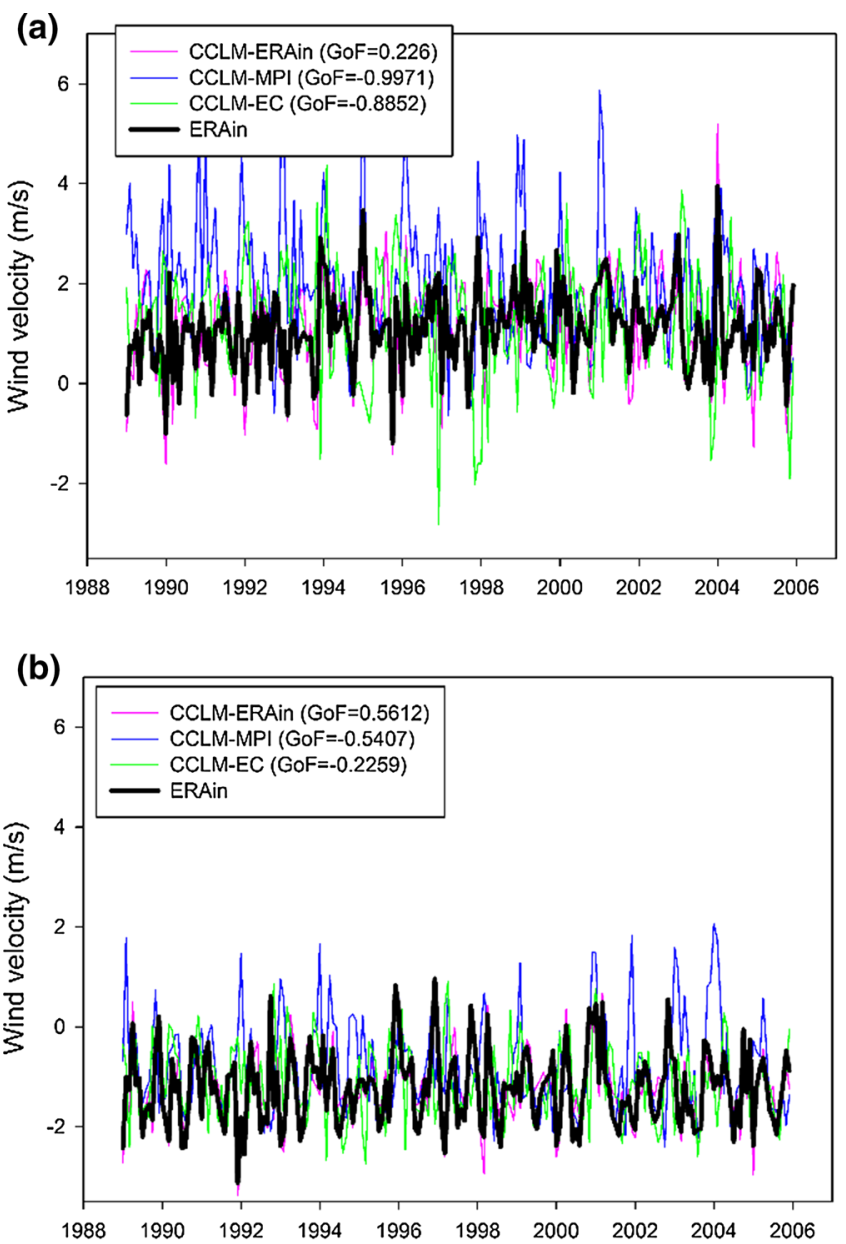

Fig. 5 a Mean monthly U10 component of the wind over the Mediterranean for the ERAin dataset and from the different RCM realizations. b Mean monthly V10 component of the wind over the Mediterranean for the ERAin dataset and from the different RCM

the central part of this sub-basin and the northern Adriatic Sea showing SST anomalies outside the error limits.

Regarding CCLM-MPI driven simulations, mean SST field using the uncorrected variables show a mean cold bias of $-1.2{ }^{\circ} \mathrm{C}$ being inside the error intervals in just $6 \%$ of the
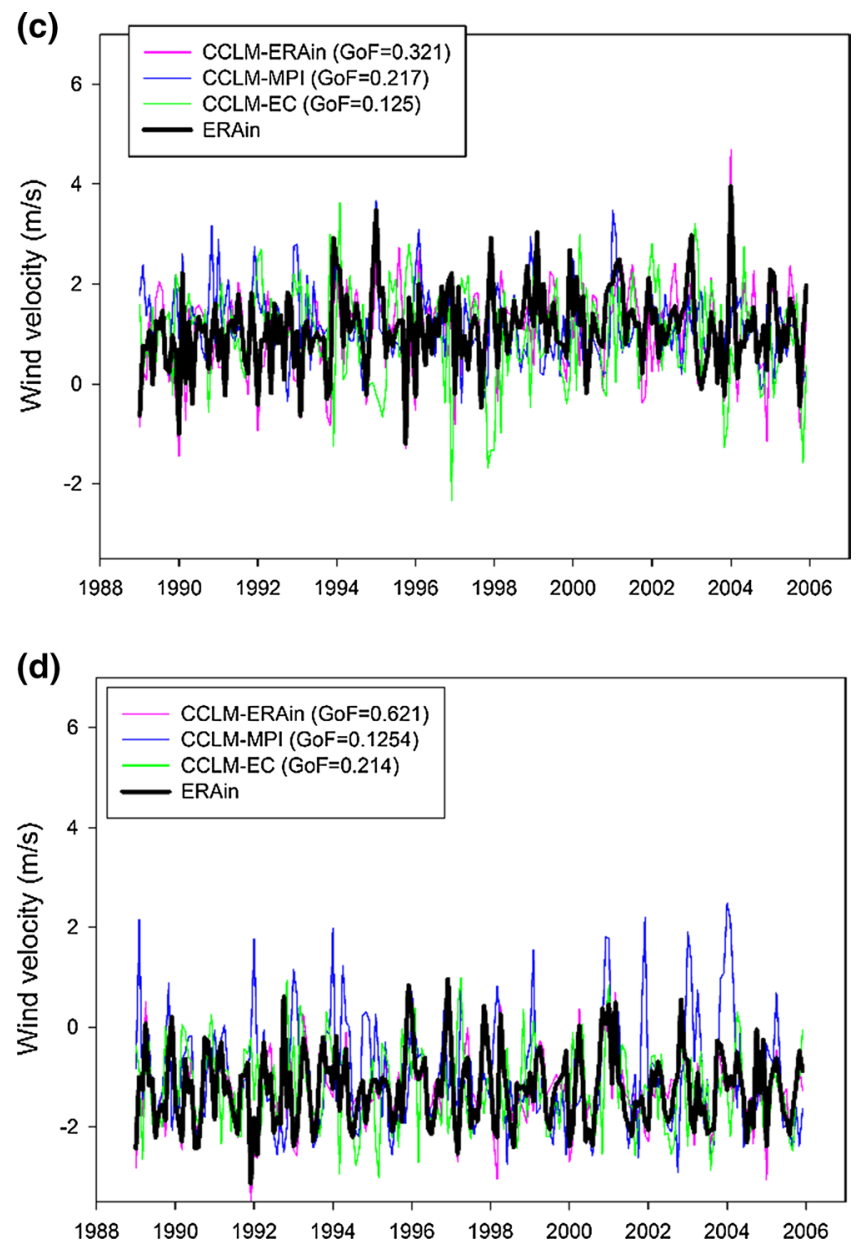

realizations. a Same as a after the bias correction. $\mathbf{d}$ Same as $\mathbf{b}$ after the bias correction. The goodness-of-fit (GoF) computed by using the normalized root mean square error is indicated beside each time series

basin (Fig. 6d) as only some areas within the Alboran Sea and the farthest eastern Mediterranean are within the limits. When the bias correction is applied, the mean anomaly decreases to $-0.47^{\circ} \mathrm{C}$ and the area inside the error range is $51 \%$ (Fig. $6 \mathrm{~g}$ ) with improved fitting throughout the 
(a)

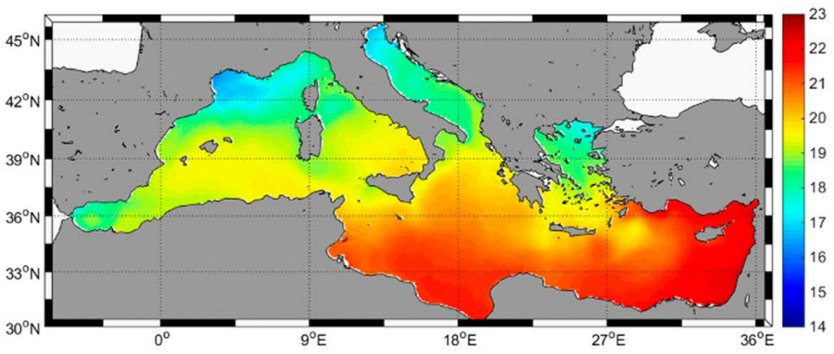

(c)

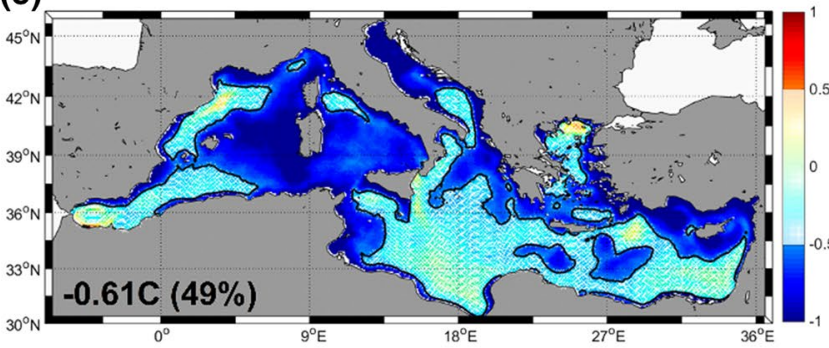

(d)

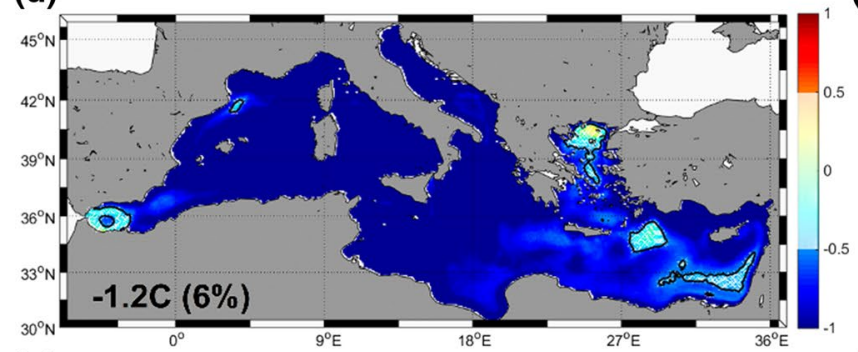

(e)

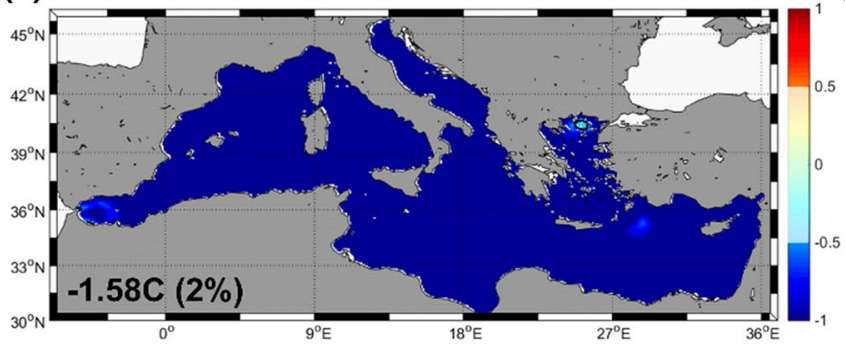

Fig. 6 a Spatial map of climatologic SST values during 1989-2005 from Pathfinder satellite data. b Climatologic SST anomalies (model data-satellite data) for the ERAin driven run. c-e Climatologic SST anomalies (model data-satellite data) for the different uncorrected model runs. f-h Climatologic SST anomalies (model data-satellite

majority of the eastern basin and along the coastal zones of the western basin.

Finally, the uncorrected CCLM-EC driven simulation shows a mean SST difference with satellite of $-1.6{ }^{\circ} \mathrm{C}$ being inside the observational error range in barely $2 \%$ of the basin (Fig. 6e). After the bias correction, the mean anomaly is reduced to $-0.85{ }^{\circ} \mathrm{C}$ and the area where they are inside the error range is around $20 \%$ of the basin (Fig. 6h), only including some regions of the far east basin, within the Alboran Sea and in some coastal areas. (b)

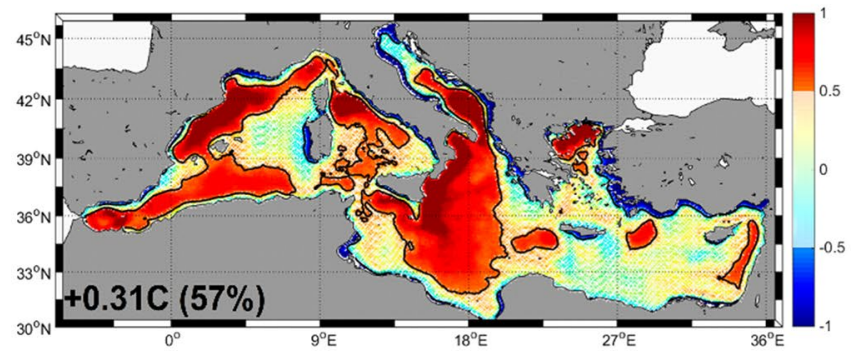

(f)

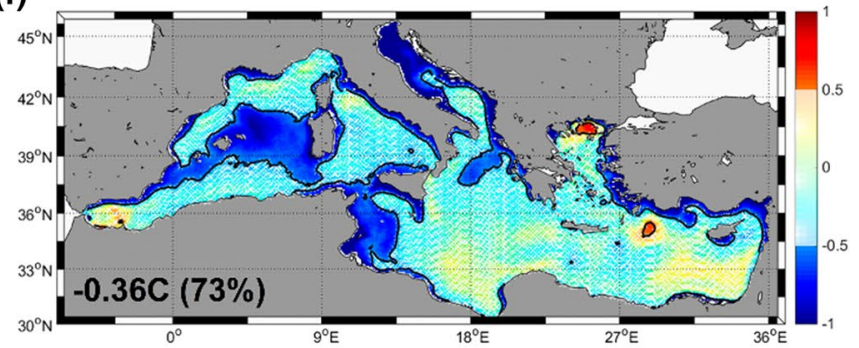

(g)

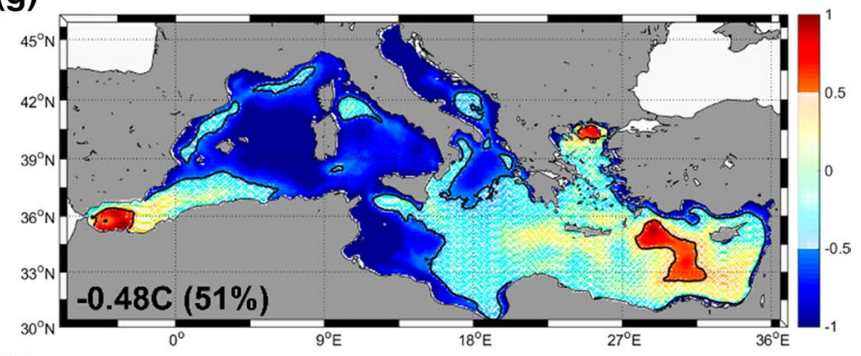

(h)

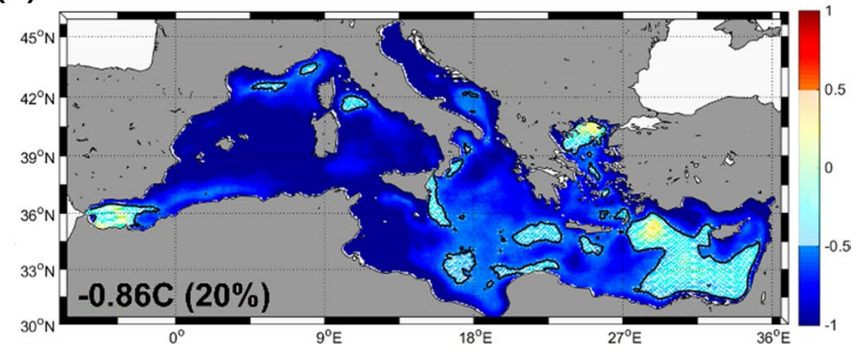

data) for the different corrected model runs. Whitened areas in panels $\mathbf{b}$ to $\mathbf{h}$ indicate where the mean anomaly between model and satellite is within the range $\pm 0.5^{\circ} \mathrm{C}$ (isolines indicated with black contours). The mean basin wide anomaly and the $\%$ of the basin within the error range are indicated for each panel

The comparison of the SST maps for winter months (January, February and March) are shown in Fig. 7. The mean anomaly for the ERAin driven run is $+0.51{ }^{\circ} \mathrm{C}$ with $38 \%$ of the basin within the nominal satellite error range (Fig. 7b). For CCLM-ERAin runs the bias correction reduces the mean deviation from -0.12 to $-0.06{ }^{\circ} \mathrm{C}$ (Fig. 7c, f) although the area within the error range did not significantly change (from 76 to $74 \%$ ). The same can be said for the CCLM-MPI driven runs (Fig. 7d, g) as the bias correction reduces the mean SST bias from 
(a)

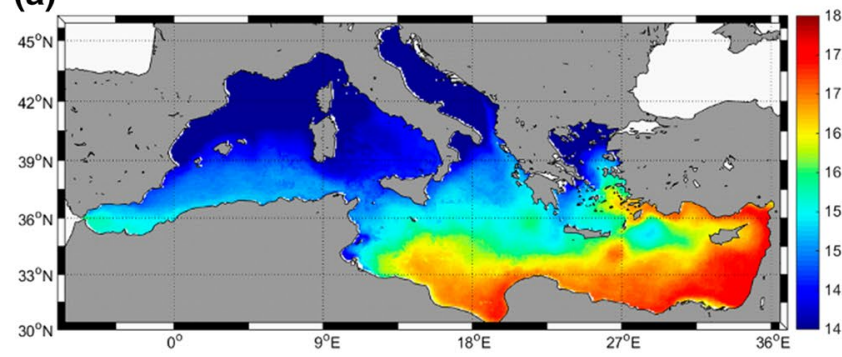

(c)

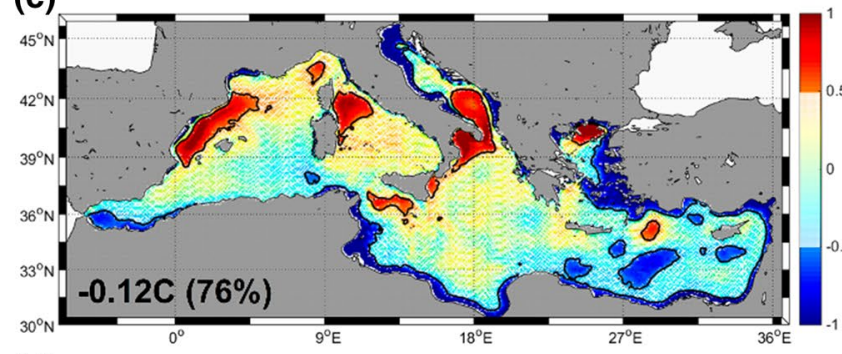

(d)

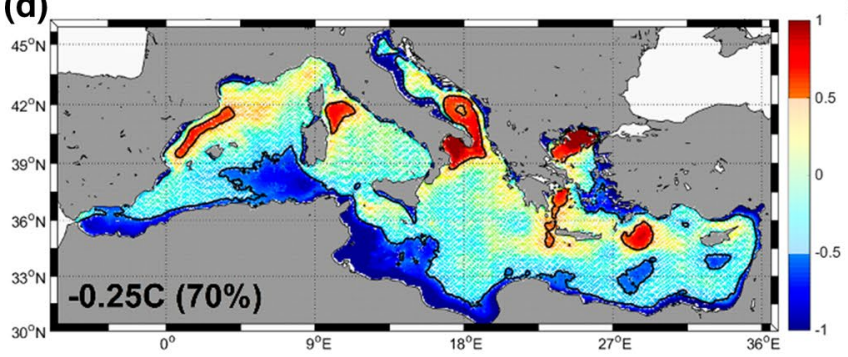

(e)

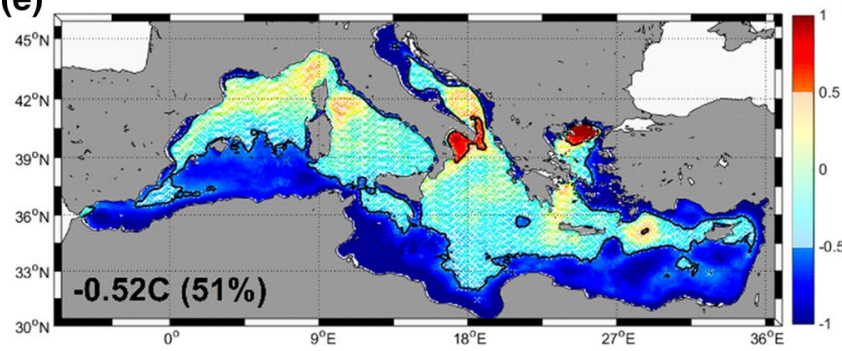

Fig. 7 a Spatial map of climatologic winter (January, February, March) SST values during 1989-2005 from Pathfinder satellite data. b Climatologic SST winter anomalies (model data-satellite data) for the ERAin driven run. c-e Climatologic SST winter anomalies (model data-satellite data) for the different uncorrected model runs. f-h Climatologic SST winter anomalies (model data-satellite data)

-0.25 to $+0.12{ }^{\circ} \mathrm{C}$ but no large changes in the well represented area is detected (70 to $68 \%$ ). Finally for CCLMEC driven runs the bias correction largely reduces the mean bias (from -0.52 to $-0.17{ }^{\circ} \mathrm{C}$ ) and also increases the region within the observational error range (from 51 to $76 \%$ ).

Figure 8 shows the corresponding SST maps for summer months (June, July and August). For the ERAin driven run (Fig. 8b) the mean bias is quite low $\left(+0.38{ }^{\circ} \mathrm{C}\right)$ although there is a large fraction of the basin (almost $60 \%$ ) outside the error limits. In the CCLM-ERAin run there is a mean (b)

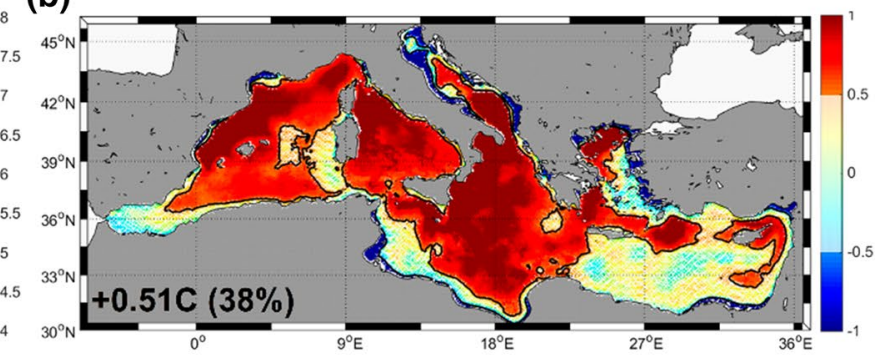

(f)

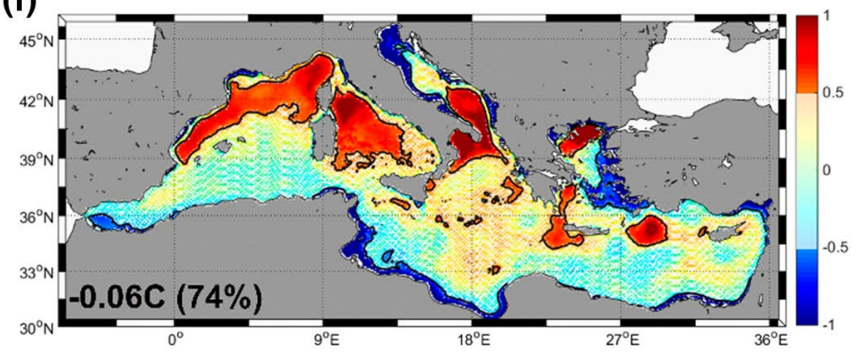

(g)

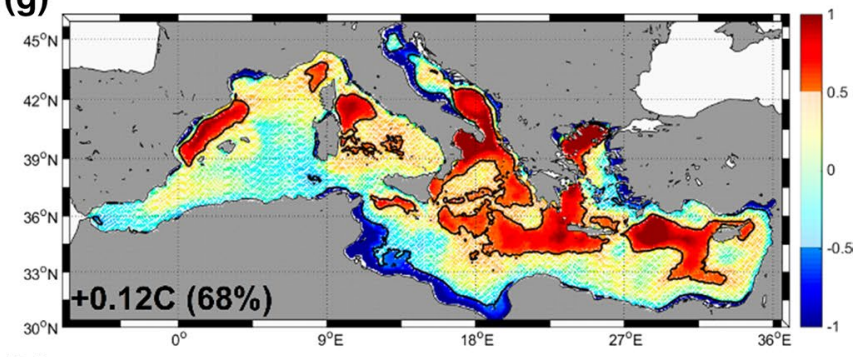

(h)

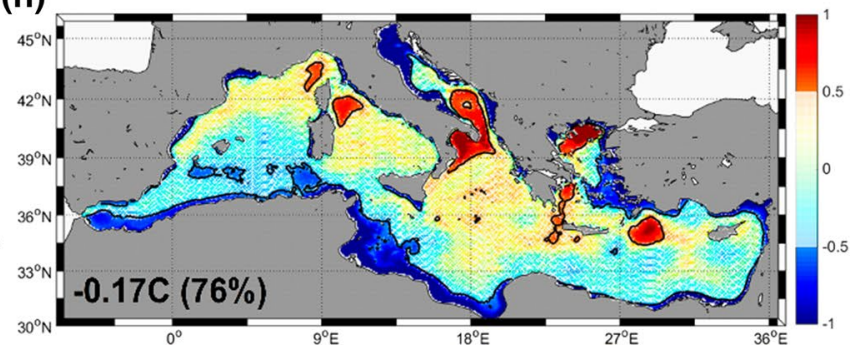

for the different corrected model runs. Whitened areas in panels $\mathbf{b}$ to $\mathbf{h}$ indicate where the mean anomaly between model and satellite is within the range $\pm 0.5^{\circ} \mathrm{C}$ (isolines indicated with black contours). The mean basin wide anomaly and the $\%$ of the basin within the error range are indicated for each panel

bias of $-0.89{ }^{\circ} \mathrm{C}$ with only $33 \%$ of the basin within the error range before the bias correction (Fig. 8c). This numbers improve to a mean bias of $-0.54{ }^{\circ} \mathrm{C}$ and a good representation of $40 \%$ of the basin when the bias correction is applied (Fig. 8f). In the CCLM-MPI runs (Fig. 8d, g) the mean bias reduces from -1.9 to $-0.79{ }^{\circ} \mathrm{C}$ and the area within the error range increases from 8 to $33 \%$ when the bias correction is applied. Finally for the CCLM-EC runs (Fig. 8e, h) the bias correction reduces de mean SST deviation from $-2.4 \mathrm{C}$ to $-1.2{ }^{\circ} \mathrm{C}$ and increases the area within the error range from 2 to $19 \%$. 
(a)

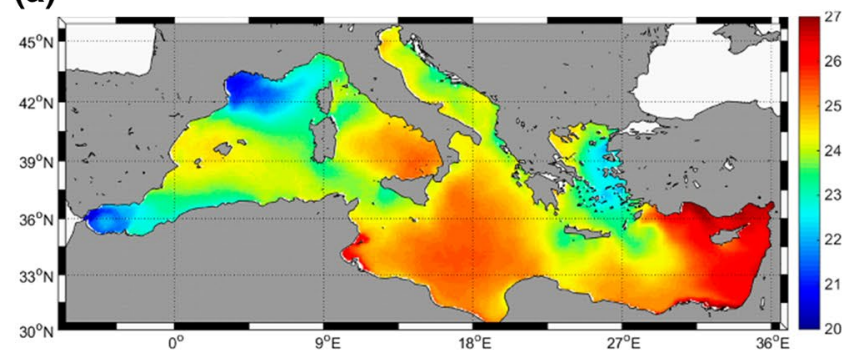

(c)

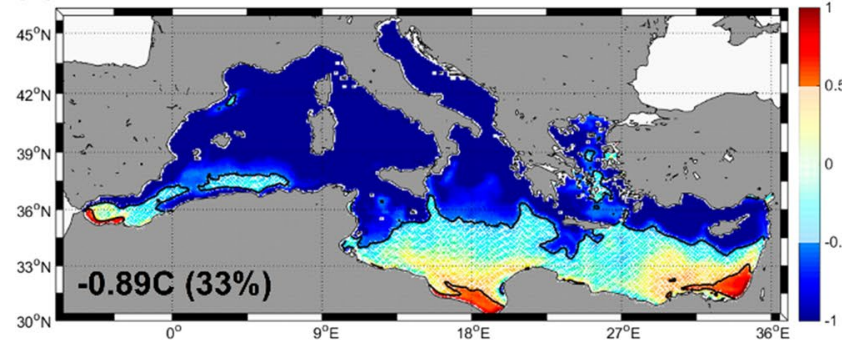

(d)

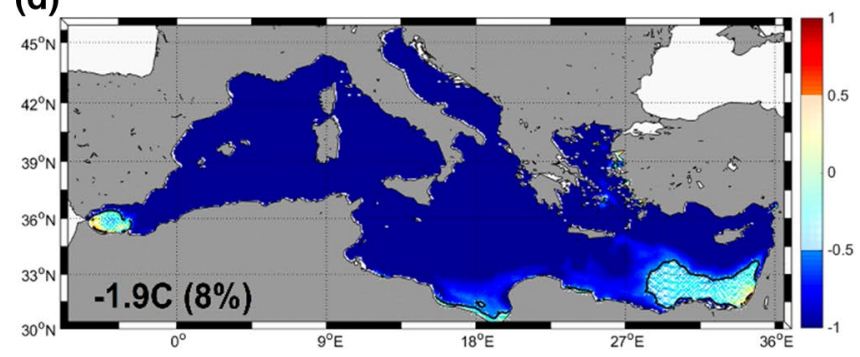

(e)

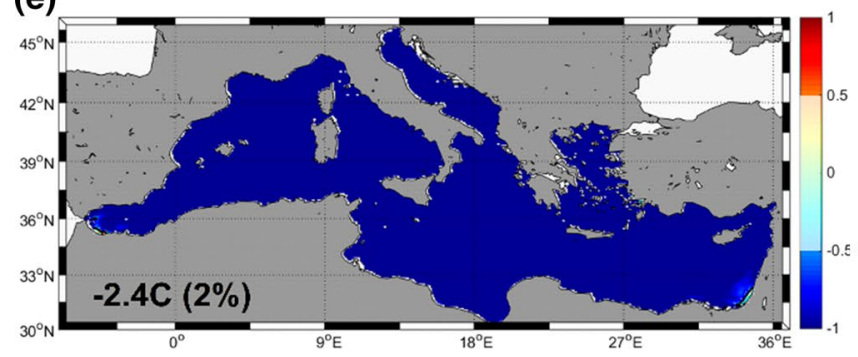

Fig. 8 a Spatial map of climatologic summer (June, July, August) SST values during 1989-2005 from Pathfinder satellite data. b Climatologic SST summer anomalies (model data-satellite data) for the ERAin driven run. c-e Climatologic SST summer anomalies (model data-satellite data) for the different uncorrected model runs. f-h Climatologic SST summer anomalies (model data-satellite data) for the

The effects of bias-correction on surface currents are shown in Fig. 9. For the ERAin driven runs, the mean surface water velocities (Fig. 9a) show some of the wellknown features in the basin such as the anticyclonic circulation in the western Alboran Sea, the westerly flowing Northern Current (NC) in the Gulf of Lion, the cyclone in the southern Adriatic and the general cyclonic circulation along the coast of the eastern Mediterranean (e.g., Millot and Taupier-Letage 2005). Also, some discrepancies with the typical surface current pattern do occur, for example, (b)

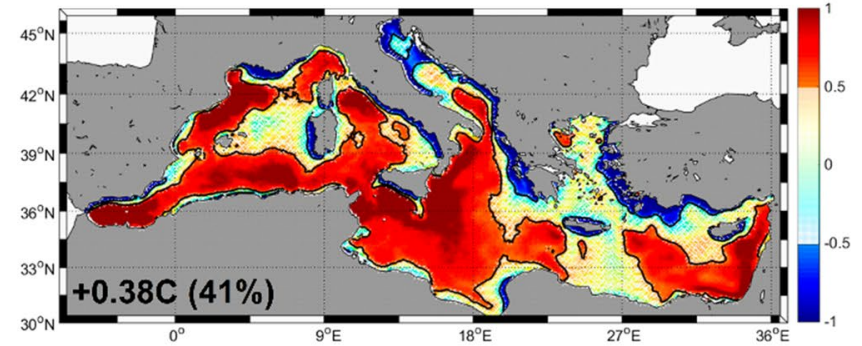

(f)

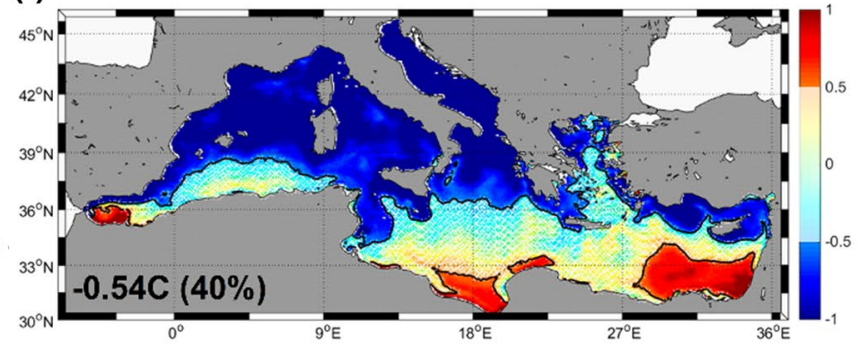

(g)

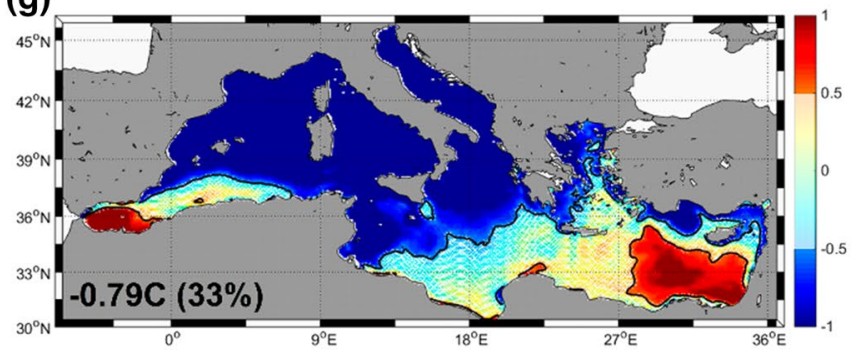

(h)

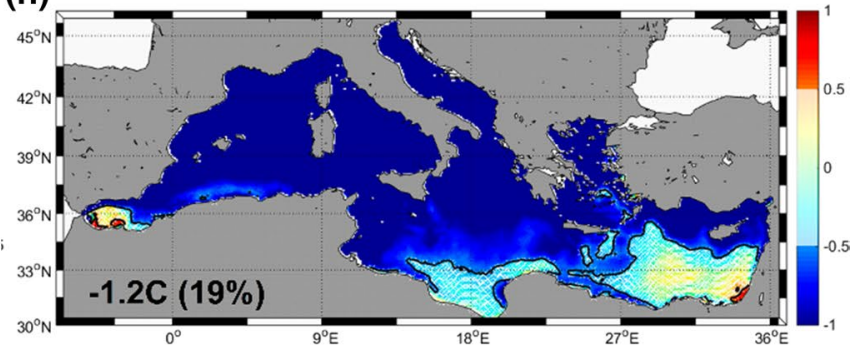

different corrected model runs. Whitened areas in panels $\mathbf{b}$ to $\mathbf{h}$ indicate where the mean anomaly between model and satellite is within the range $\pm 0.5^{\circ} \mathrm{C}$ (isolines indicated with black contours). The mean basin wide anomaly and the $\%$ of the basin within the error range are indicated for each panel

in the eastern Alboran Sea where no anticyclone is formed and within the Balearic Sea, where water flows northwards rather than southwards. Another anomaly is the very intense coastal jet simulated by all model runs west of the Sicily Strait and a weaker-than-observed mid-Ionian jet. When forcing the ocean model with atmospheric variables from CCLM-ERAin (Fig. 9b) the main water circulation is quite similar although some of the problems previously mentioned in the Balearic Sea are reduced and some features (such as the cyclone in the Adriatic) are strengthened 


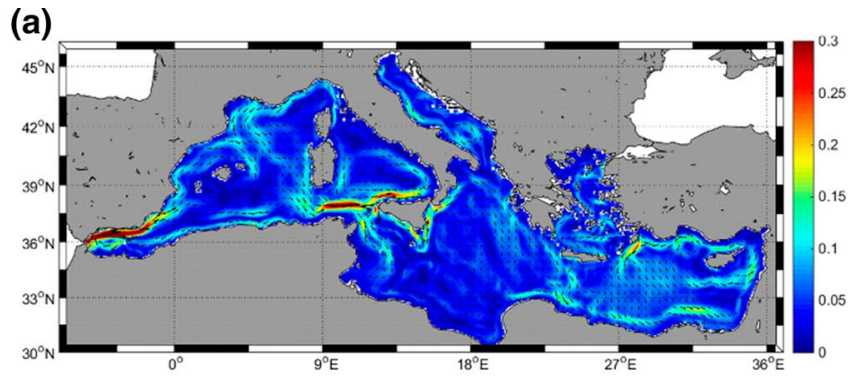

(b)

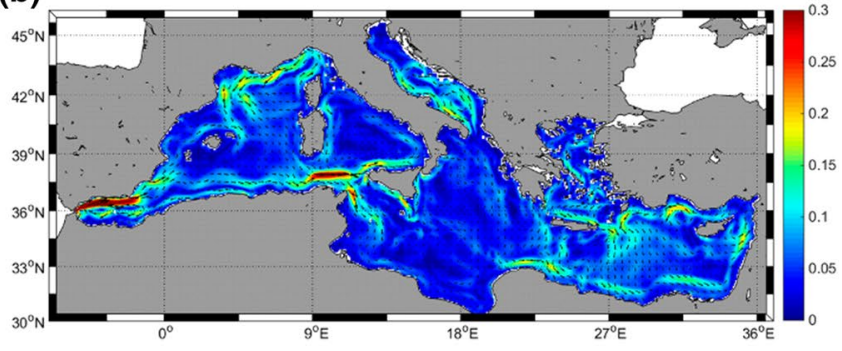

(d)

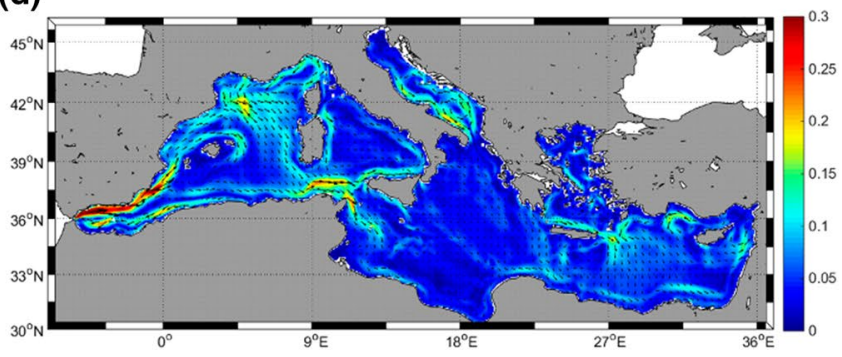

(f)

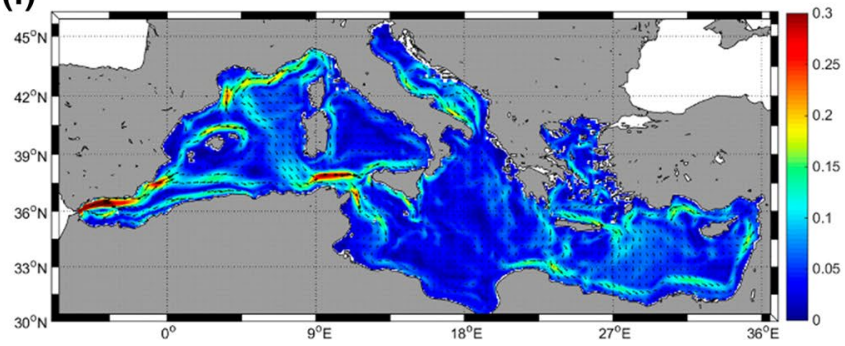

Fig. 9 a Mean annual surface $(15 \mathrm{~m})$ currents $(\mathrm{m} / \mathrm{s})$ for the ERAin forced run. b Mean annual surface $(15 \mathrm{~m})$ currents $(\mathrm{m} / \mathrm{s})$ for the CCLM-ERAin forced run. c Mean annual surface $(15 \mathrm{~m})$ currents $(\mathrm{m} / \mathrm{s})$ for the CCLM-ERAin corrected forced run. d Mean annual surface $(15 \mathrm{~m})$ currents $(\mathrm{m} / \mathrm{s})$ for the CCLM-MPI forced run. e Mean

in better agreement with the literature (e.g., SiokouFrangou et al. 2010). After applying the bias-correction to the CCLM-ERAin variables, the simulated surface currents (Fig. 9c) did not fundamentally change, although the northern current becomes stronger.

For the CCLM-MPI forced simulation (Fig. 9d), simulated surface currents in the western Mediterranean are fundamentally different to previous results. There is a very strong northerly flowing coastal jet following the Iberian slope and entering into the Balearic Sea. The presence of this jet makes the northern current to turns southward in (c)

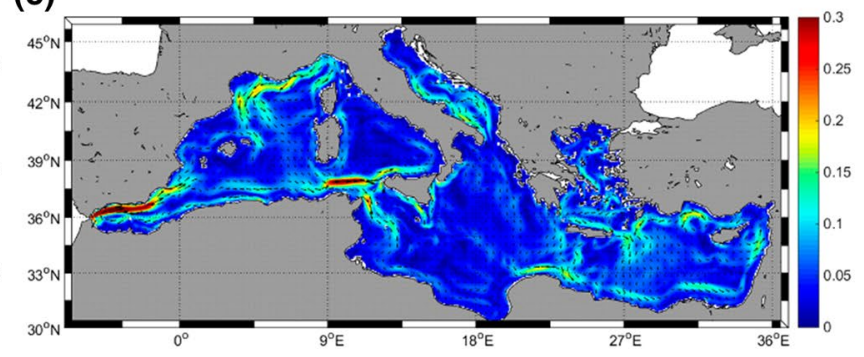

(e)

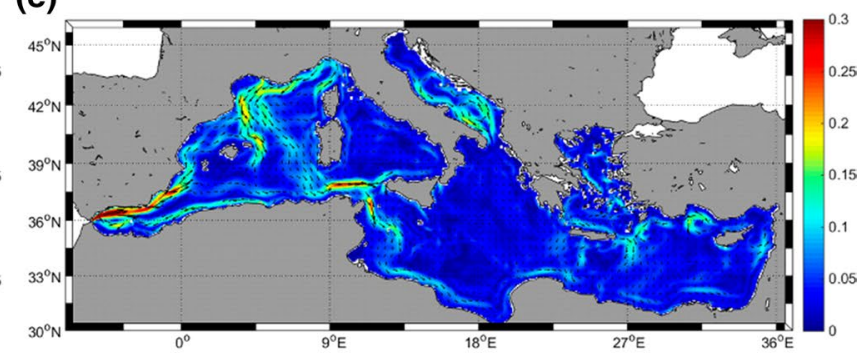

(g)

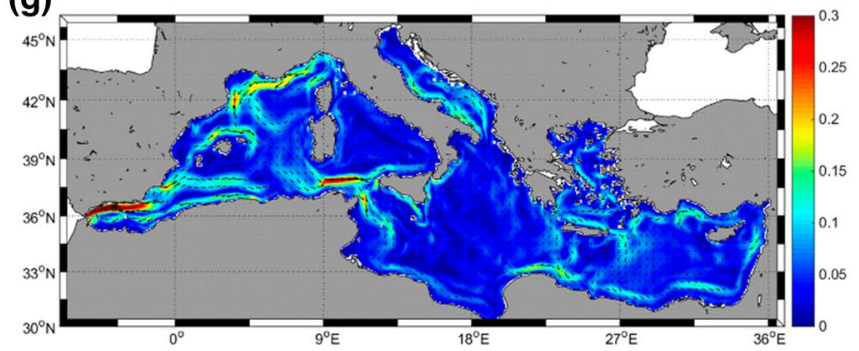

annual surface $(15 \mathrm{~m})$ currents $(\mathrm{m} / \mathrm{s})$ for the CCLM-MPI corrected forced run. f Mean annual surface $(15 \mathrm{~m})$ currents $(\mathrm{m} / \mathrm{s})$ for the CCLM-EC forced run. $\mathbf{g}$ Mean annual surface $(15 \mathrm{~m})$ currents $(\mathrm{m} / \mathrm{s})$ for the CCLM-EC corrected forced run

front of the Gulf of Lion, creating a very unrealistic pattern in the NW Mediterranean region. After bias-correcting the atmospheric variables, the CCLM-MPI forced run shows an improvement in simulated currents in the western Mediterranean (Fig. 9e). The northerly flowing coastal jet is weakened so the northern current does not suffer such a strong deflection to the south. However, the circulation pattern in the NW Mediterranean, although improved, is far from being satisfactory.

In the case of the CCLM-EC forced simulation, simulated surface currents (Fig. 9f) show a better spatial pattern, with a 


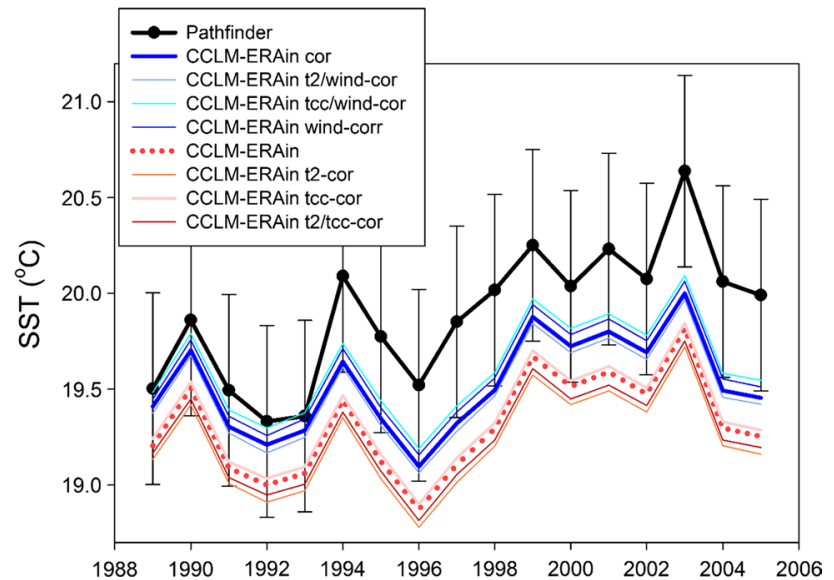

Fig. 10 Mean annual SST time series from the different CCLMERAin individually corrected model runs. It includes the totally corrected run (dark blue line) and the uncorrected run (dotted red line). The individual corrections are indicated in the legend. The satellite annual mean SST is also included (black line) for comparison

strong northern current and the right water movement within the Balearic Sea (e.g., Salat 1995) although still a too-strong northerly current along the Levantine Iberian coast is simulated. The effect of applying the bias-correction to the atmospheric variables from CCLM-EC does not fundamentally change the surface currents pattern (Fig. 9g) and only a slight reinforcement of the northern current intensity is noticeable.

\subsection{Identifying the effects of each individual correction}

However, the joint correction of all atmospheric variables shown above does not provide any quantitative information on which one is more crucial to improve the simulated SST fields. Henceforth, a new series of simulations was performed applying the bias correction to each one of the individual atmospheric variables and to the combination (two by two) from the CCLM-ERAin realization. The annual time series of SST from this new set of simulations are shown in Fig. 10 along with the SST obtained using the uncorrected variables and from using the totally corrected values. It is clear to see that only if wind correction is included (blue lines in Fig. 10) simulated SST move significantly from the uncorrected simulation; only correcting $\mathrm{t} 2$, tcc or the combination of both did not strongly change model results. In all the simulations where wind correction took place (only wind, or the combinations wind/tcc and wind/t2) the SST were very close to the results applying the whole correction. From these results, it is quite clear that for this particular realization (CCLM-ERAin) wind is the most important atmospheric variable to be corrected in order to improve SST computations.

To test if the same holds true for the GCM-driven realizations, we performed new simulations forcing the ocean model with partially corrected RCMs data; one with only
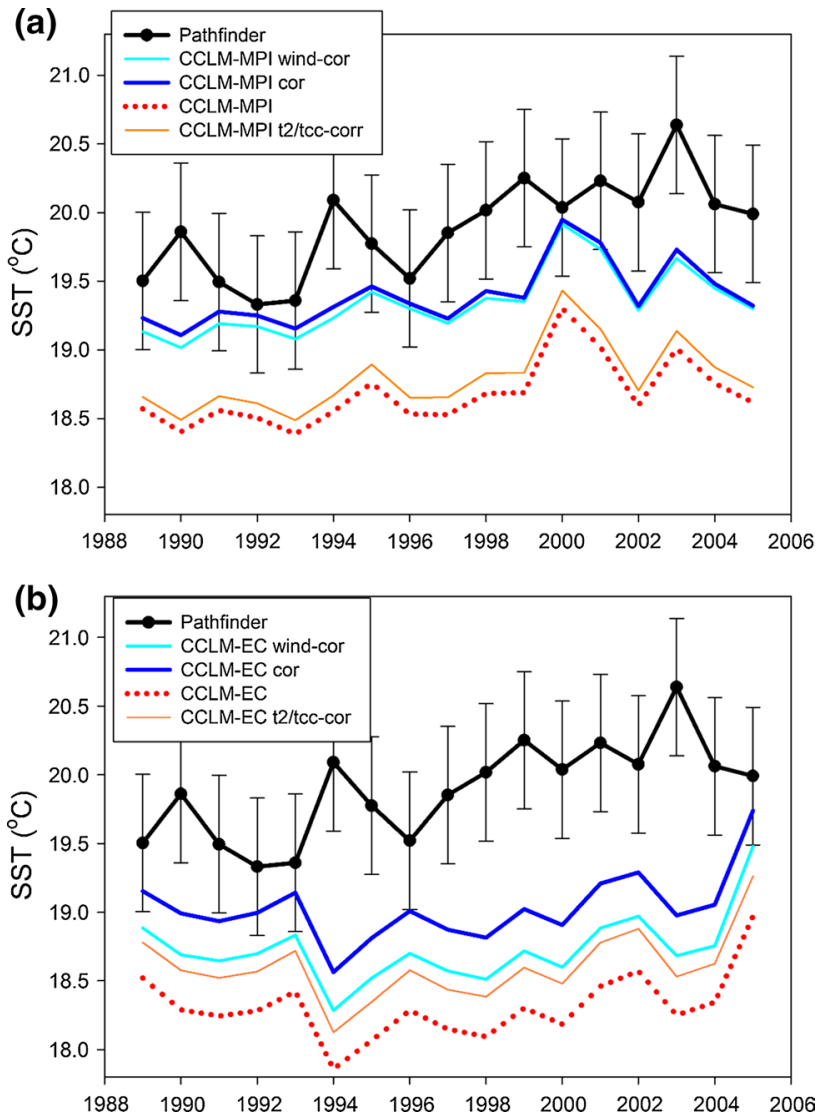

Fig. 11 a Mean annual SST time series from the different CCLMMPI individually corrected model runs. The satellite annual mean SST is also included (black line) for comparison. $\mathbf{b}$ as panel $\mathbf{a}$ but for CCLM-EC model runs

t2 and tcc corrected and another with only wind intensity corrected. For the CCLM-MPI realization data (Fig. 11a) the results are quite similar to the described above, the most important variable to be corrected is wind intensity, only correcting $\mathrm{t} 2$ and tcc makes very small difference with respect to the uncorrected run. On the contrary, for the CCLM-EC realization (Fig. 11b) the combined effect of $\mathrm{t} 2$ and tcc is quite important, almost of the same magnitude as the wind correction effect. In this latter case only using the full correction makes the SST to come closer to observed values.

\subsection{Consequences of the bias correction on basin-wide properties}

In order to evaluate further the consequences of biascorrecting atmospheric variables on the simulated vertical properties of the Mediterranean basin a comparison of winter (January, February, March) mean mixed layer depth (MLD) has been conducted for each of the model realizations (Fig. 12). The MLD has been computed as 


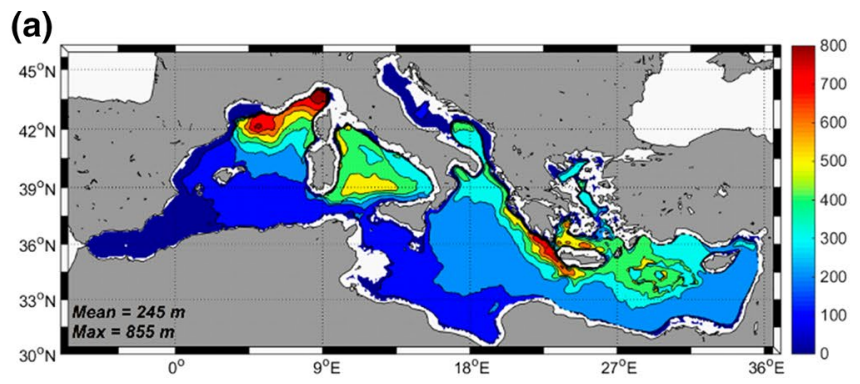

(b)

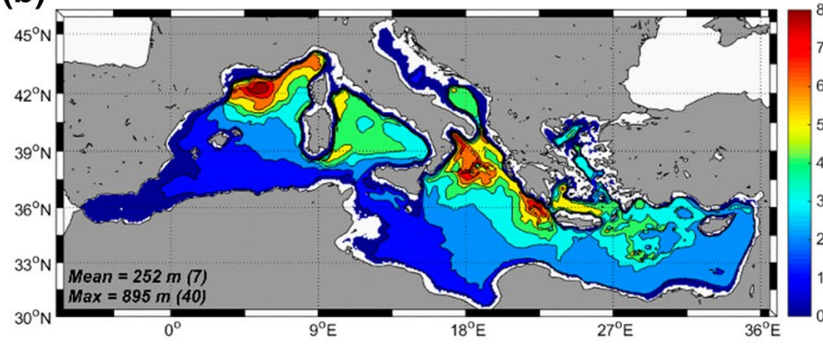

(d)

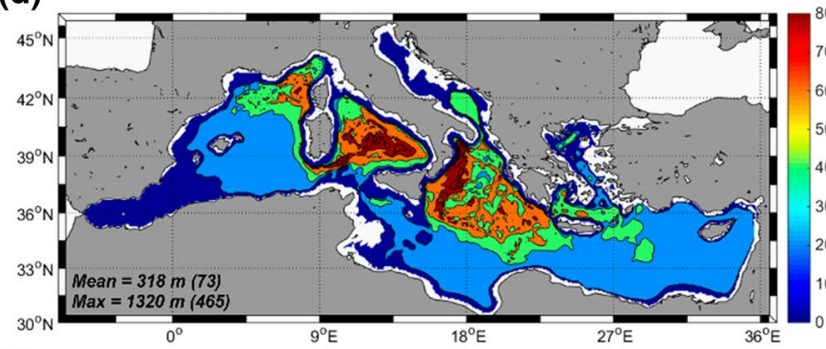

(f)

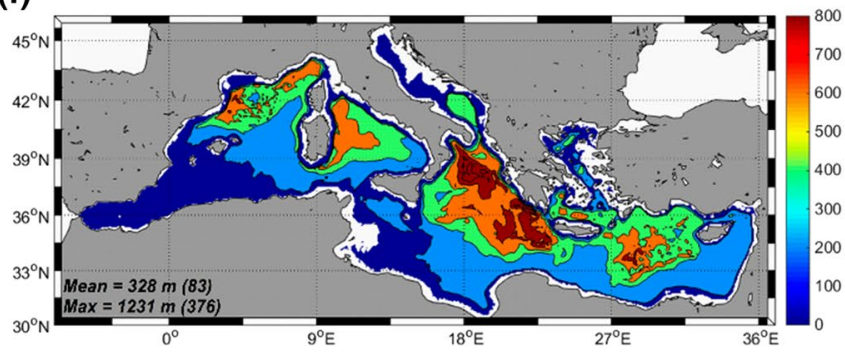

Fig. 12 a Mean annual winter (JFM) mixed layer depth (MLD in m) for the ERAin forced run. b Mean annual winter (JFM) mixed layer depth (MLD in $\mathrm{m}$ ) for the CCLM-ERAin forced run. $\mathbf{c}$ Mean annual winter (JFM) mixed layer depth (MLD in $\mathrm{m}$ ) for the CCLM-ERAin corrected forced run. d Mean annual winter (JFM) mixed layer depth (MLD in $\mathrm{m}$ ) for the CCLM-MPI forced run. e Mean annual winter (JFM) mixed layer depth (MLD in $\mathrm{m}$ ) for the CCLM-MPI corrected

the depth in which the potential density difference with the surface is larger than $0.1 \mathrm{~kg} / \mathrm{m}^{3}$. The ERAin forced run (Fig. 12a) simulated a winter MLD pattern similar to the one described in the literature (e.g., D'Ortenzio et al. 2005; Houpert et al. 2015), with deep MLD in the Gulf of Lion and around Crete (southern Aegean Sea). However, this model run simulates very deep MLD in the Ligurian Sea and also quite large values $(\sim 500 \mathrm{~m})$ in the Tyrrhenian basin which are not typical features described in the literature (e.g., Somot et al. 2006 and references therein). (c)

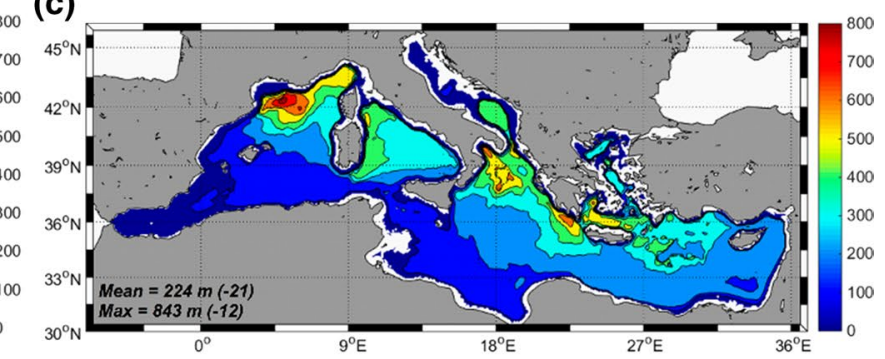

(e)

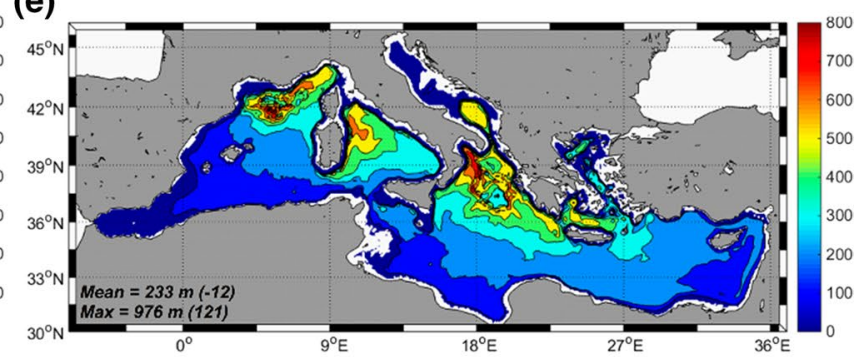

(g)

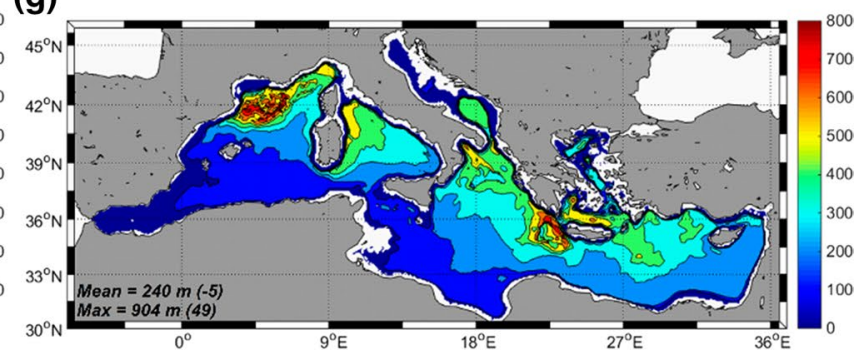

forced run. f Mean annual winter (JFM) mixed layer depth (MLD in $\mathrm{m}$ ) for the CCLM-EC forced run. $\mathrm{g}$ Mean annual winter (JFM) mixed layer depth (MLD in $\mathrm{m}$ ) for the CCLM-EC corrected forced run. Within each panel the mean and maximum MLD value for each run are indicated. Numbers in brackets are the difference with respect to the ERAin forced run (panel a)

When using the CCLM-ERAin realization to force the ocean model (Fig. 12b) the winter MLD pattern is similar to the one described above, although some small differences could be observed. In this case MLD is shallower in the Ligurian and Tyrrhenian Sea although larger values are simulated for the northern Ionian. At the same time, MLD values in the southern Adriatic Sea are larger than in the ERAin-forced simulation. If the corrected atmospheric variables from CCLM-ERAin are used (Fig. 12c) a substantial improvement could be seen with MLD values being 
Table 6 Bottom water layer (> $600 \mathrm{~m}$ ) thermohaline properties for the different simulations and from the MEDATLAS dataset

\begin{tabular}{lllll}
\hline Forcing model & $\Delta \mathrm{T}\left({ }^{\circ} \mathrm{C} / \mathrm{y}\right)$ & $\Delta \mathrm{S}(\mathrm{psu} / \mathrm{y})$ & Mean $\mathrm{T}\left({ }^{\circ} \mathrm{C}\right)$ & Mean S \\
\hline ERAin & 0.022 & 0.010 & 13.75 & 38.73 \\
CCLM-ERAin (uncorrected/corrected) & $0.028 / 0.027$ & $0.011 / 0.010$ & $13.80 / 13.78$ & $38.72 / 38.71$ \\
CCLM-MPI (uncorrected/corrected) & $0.03 / 0.022$ & $0.013 / 0.011$ & $13.77 / 13.74$ & $38.71 / 38.69$ \\
CCLM-EC (uncorrected/corrected) & $0.019 / 0.021$ & $0.010 / 0.009$ & $13.70 / 13.71$ & $38.69 / 38.68$ \\
DATA (MEDATLAS (1989-2002)) & 0.004 & 0.0016 & 13.56 & 38.69 \\
\hline
\end{tabular}

The rate of change $(\Delta)$ has been computed adjusting the mean annual values to a linear trend and computing its slope. For the CCLM-forced runs the first number correspond to the uncorrected values and the second to the bias-corrected results reduced in the Ligurian, Tyrrhenian and Ionian Seas and with the three main convection sites (Gulf of Lion, Southern Adriatic and Crete) showing large MLD values. In both simulations using CCLM-ERAin variables (uncorrected and corrected) the mean and maximum MLD values are very similar to the ones obtained from the ERAin-forced runs (see numbers within panels a) to c) in Fig. 12).

On the other hand, if CCLM-MPI variables are used to force the ocean model, the winter MLD distribution is certainly different (Fig. 12d). In this case, almost the entire Tyrrhenian and Ionian seas shows very large MLD values with a maximum being 460 deeper than the one simulated with ERAin forcing. The effects of bias-correcting the atmospheric variables could be easily seen in Fig. 12e. The Gulf of Lion, southern Adriatic Sea and Crete appear as deep convection zones although some other zones such as the northern Ionian Sea and the western Tyrrhenian also present deep MLD. A quite similar pattern could be observed when comparing the uncorrected and corrected CCLM-EC forced runs (Fig. 12f, g). Without the bias correction, winter MLD is typically very deep in large portion of the Mediterranean basin (Fig. 12f) with a mean value $83 \mathrm{~m}$ larger than in the ERAin simulation and a maximum located $\sim 370$ m deeper. After applying the bias correction to the atmospheric variables, the winter MLD distribution and mean values (Fig. 12g) are much more similar to the ones obtained with the ERAin forcing (Fig. 12a) although, again, some deep convection could be observed in the north-western Ionian Sea.

Finally, the termohaline characteristics of the deeper water layers $(>600 \mathrm{~m})$ have been examined in the different model runs (Table 6). First, the mean rate of change of temperature and salinity over the 15 years of simulation is computed for the ERAin driven runs and the different RCM driven runs (with and without correction). As shown in Table 6, in the ERAin-forced run there are warming and salination trends of the deep water layers $\left(\sim 0.02{ }^{\circ} \mathrm{C} / \mathrm{y}\right.$ and $0.01 \mathrm{psu} / \mathrm{y})$. These trends are larger than typically reported in the literature from data (Table 6) and could be related with an overestimation of vertical convection by the GETM setup used here (see discussion in Llasses et al. this issue).
Very similar values are found for all the RCM-forced simulations with a negligible effect of the bias correction on the temporal evolution of temperature and salinity of this deep water layer. Also the mean temperature and salinity of this deep water mass are very similar to the values obtained from the MEDATLAS dataset and show very little variation with and without the bias correction as maximum temperature change is $\sim 0.03{ }^{\circ} \mathrm{C}$ while maximum salinity deviation is 0.02 (Table 6).

\section{Discussion}

The presence of biases in simulated surface ocean conditions when using atmospheric models' variables to force ocean models is not a new issue for the Mediterranean basin and has been described elsewhere (Sanchez-Gomez et al. 2011; Boberg and Christensen 2012). These biases have strong implications when trying to create future scenarios for this marine basin as simulated changes could only be analyzed in terms of relative changes with respect to present-day situation (e.g., Somot et al. 2006; Adloff et al. 2015).

Sea surface temperatures biases are especially problematic if changes in biological production want to be addressed. An underestimation of present day SST (the normal bias described in several modeling works) typically implies a weaker vertical stratification as the deeper parts of the basin are much less affected by atmospheric forcing. Hence, water column stability is typically underestimated, implying more easy mixing of surface and deeper waters and, hence, larger fertilization of the euphotic layer (Vichi et al. 2003). At the same time, simulated surface currents and density fronts could very likely not be correctly simulated so the strength of frontal circulation and associated biological productivity (e.g., Oguz et al. 2014) should not be well captured. Thus, getting satisfactorily the present-day surface conditions is a necessary prerequisite to model plausible future scenarios. We have shown in the present contribution that a much better agreement between observed SST and forced ocean model simulation 
could be obtained by applying appropriate bias-correction procedures to some key atmospheric variables provided by dynamical downscaling with RCM (Fig. 2).

\subsection{The added value of using RCMs to force a Mediterranean ocean model}

Comparing the results using the 'evaluation run' (i.e., CCLM-ERAin realization) and those using directly the reanalysis data (ERAin) provides an insight on the bias induced by the RCM alone. With this comparison the effect of the downscaling provided by the RCM could be separated from the consequences deriving from the lateral boundary conditions (e.g., Ehret et al. 2012). Without performing biascorrection the mean differences between the ERAin run and the CCLM-ERAin run with respect to satellite data are not statistically significant at $99 \%$ level (Table 2) although the former has a lower absolute bias $\left(0.13{ }^{\circ} \mathrm{C}\right)$ than the second $\left(0.53{ }^{\circ} \mathrm{C}\right)$. Spatially, the ERAin forced run proves also to have a better fit with satellite climatology with $57 \%$ of the basin correctly simulated while the CCLM-ERAin forced run is within observational error in just $49 \%$ of the basin (Fig. 6). Both model runs are better in representing the SST in the eastern Mediterranean basin than the western basin. However, in this comparison (Fig. $6 \mathrm{~b}$ and c) it could be seen that CCLM-ERAin performs better near the coast (especially in the western Mediterranean) compared to ERAin, which may be an effect of its higher horizontal spatial resolution $\left(0.11^{\circ}\right)$. This improvement of fitting between model and satellite in the coastal fringe when using downscaling regional models has been also shown when using other reanalysis products as ERA40 (Sanchez-Gomez et al. 2011) and NCEP/NCAR (Garcia-Sotillo et al. 2005). Coastal regions are fundamental places for marine productivity and where most of the Mediterranean fisheries takes place (e.g., Coll et al. 2013) so having a satisfactory representation of the hydrodynamic conditions in such areas is a fundamental improvement for biogeochemical applications obtained by the use of adequate RCMs.

The horizontal distribution of surface currents does not fundamentally change when using CCLM-ERAin to force the ocean model (Fig. 9b) with respect to those simulated using ERAin (Fig. 9a). The most evident differences are found, once more, in coastal regions such as the Gulf of Lion and within semienclosed basins such as the Adriatic Sea. In both places, simulated currents using CCLMERAin are stronger than when using ERAin. Also coastal currents in the Eastern Mediterranean seems to be reinforced when using the RCM outputs.

In both simulations using ERAin and CCLM-ERAin forcing (Fig. 12a, b), the winter convection zones are simulated to happen on the usually described places, such as the Gulf of Lion (e.g., Schott et al. 1996), around Crete (e.g.,
Lascaratos et al. 1993) and in the southern Adriatic (e.g., Artegiani et al. 1997). Using the higher resolution RCM results some of the problems observed in the ERAin run, such as the very deep MLD in the Ligurian Sea and the moderate MLD in the Tyrrhenian are ameliorated (Fig. 12b). However, other regions, such as the Ionian Sea show much larger MLD than typically described (e.g., Siokou-Frangou et al. 2010) or simulated with ERAin forcing (Fig. 12a).

The comparison of corrected and uncorrected variables from the CCLM-ERAin realizations shows that the used RCM did not introduce a strong bias in the air temperature (Fig. 3a) but it does induce an overestimation of cloud cover (Fig. 4, left panel) while wind speeds are in quite good agreement with the reanalysis (Fig. 5) with a mean ratio data/model of 0.9 and 1.03 for $\mathrm{U}$ and $\mathrm{V}$ respectively (Table 5). Furthermore, the difference between the computed SST using the non-corrected and corrected CCLMERAin variables are the lowest of all the tested realizations (see Fig. 2a, d) which indicates that CCLM-induced mean bias are not crucially relevant. However, performing the bias correction the atmospheric variables largely increase the percentage of the basin where SST anomalies are within the observational error (compare Fig. 6c, d).

When the CCLM-ERAin atmospheric variables are biascorrected, simulated SST values are closer to observations with a mean absolute deviation more comparable to the one obtained from the ERAin forced run (Table 1). Absolute differences between satellite data and ERAin forced run and CCLM-ERAin corrected run are almost identical although of the contrary sign (Fig. 6). Also, from the anomaly maps for the later run (Fig. 6d) it could be seen that the percentage of the basin correctly simulated is the largest of all simulations $(\sim 73 \%)$. Henceforth, the combination of a dynamic downscaling model and the bias correction technique described here is the best solution found to correctly represent Mediterranean basin-wide surface conditions. Surface currents, on the other hand, does not seem to be fundamentally changed after applying the bias-correction for this particular RCM realization (compare Fig. 9c, b).

What does change when using the bias-corrected CCLM-ERAin variables is the distribution of mean winter MLD (Fig. 12c) as the overestimation of the MLD in the Tyrrhenian and Ionian Seas is largely reduced (compared with Fig. 12b), while still showing the typical convection zones already described above.

Henceforth, CCLM seems to be a good candidate as RCM to be used to force our Mediterranean Sea ocean model given that it is forced by appropriate lateral boundary conditions. A large fraction of the biases described below for the GCMs-driven realizations could, thus, be attributed to the poorer representation of the boundary conditions by the coarser resolution GCMs and not to the downscaling performed by the RCM. 


\subsection{GCMs as boundary conditions}

When using CCLM-runs driven by GCMs at the boundaries, our analysis has shown that bias-correcting atmospheric variables is necessary in order to get reasonable mean SST values and spatial pattern for the last 15 years. When CCLM is driven by the two GCMs used here a severe underestimation of SST over the Mediterranean Sea is produced $\left(-1.28{ }^{\circ} \mathrm{C}\right.$ for CCLM-MPI and $-1.68{ }^{\circ} \mathrm{C}$ for CCLM-EC, see Table 2).

Also, substantial deficiencies on the simulated surface currents for the CCLM-MPI forced simulation could be observed (Fig. 9d). Main problems seem to be located on the western Mediterranean basin and, more specifically on the Gulf of Lion/Balearic Sea region. Here, it is typically described the presence of a strong cyclonic circulation system comprising the $\mathrm{NC}$ flowing westward along the coast of southern France (e.g., Castellon et al. 1990) and the Catalano-Balearic (CB) jet typically flowing southward in front of the Iberian coasts (e.g., Salat 1995). As indicated above, in the ERAin forced simulation (Fig. 9a) the general circulation in the area tends to follow the cyclonic motion, although the Balearic Sea circulation is not perfectly reproduced. However, for the specific case of CCLM-MPI, the $\mathrm{NC}$ is very weak and veers southwards in front of the Gulf of Lion. At the same time, the CB jet is flowing in the opposite direction than expected (i.e., north-easterly), a fact that should contribute to the southward displacement of the NC.

This very anomalous behavior of the surface current in CCLM-MPI could be linked to the severe overestimation of the zonal component of the wind (see Table 5) that should be pushing surface water masses in the region towards the east. In the spatial seasonal maps of wind intensity (Figs. S1 and S2) it could be seen that this particular CCLM realization tends to overestimate winds in the NW Mediterranean.

Simulated currents in the CCLM-EC forced simulation, on the contrary, shows a much better agreement with observations in the NW Mediterranean Sea, with the NC and CB jet flowing in the expected directions and with the right velocities (e.g., Oguz et al. 2015). Surface currents in the rest of the basin (except the Alboran Sea) seem to be quite well reproduced in both GCMs driven simulations.

On the other hand, simulated winter MLD with these two uncorrected forcings (CCLM-MPI and CCLM-EC, Fig. $12 \mathrm{~d}, \mathrm{f}$ ) is very different to the ones obtained with the ERAin forcing (Fig. 12a) or that typically described in the literature (e.g., Beuvier et al. 2010). Both the mean and maximum values of MLD are much larger than the ones obtained with ERAin forcing, indicating that for these uncorrected simulations vertical stratification is too weak possibly because of the very low water temperature in the upper layers of the water column. Too weak stratification leads to an overestimation of vertical mixing and, hence, of the depth of the mixed layer.
Considering the atmospheric variables in these two realizations, while $\mathrm{t} 2$ is quite well simulated by CCLM-MPI, a clear underestimation is observed for CCLM-EC (see Fig. 3). This is further shown by the seasonal analysis of uncorrected/corrected $\mathrm{t} 2$ in Fig. S1 and S2. Winter values are quite well simulated by both CCLM realizations (Fig. S3) although summer $\mathrm{t} 2$ are clearly lower than the reanalysis data (Fig. S4). Even after applying the bias correction summer $\mathrm{t} 2$ values are still underestimated (right column Fig. S4) although the bias is reduced to just around $0.5^{\circ} \mathrm{C}$.

These results are in fair agreement with previous works. For example, almost all models used in the CIRCE initiative underestimate $\mathrm{t} 2$ (and SST) for the historical period (Dubois et al. 2012). The SST underestimation could be as large as 3-5 degrees depending on the season. In the CIRCE models ensemble, even the ones performing better showed very little deviation of $\mathrm{t} 2$ in winter but some significant bias in summer $\left(\sim 1.5^{\circ} \mathrm{C}\right)$. Also in our uncorrected simulations the largest SST deviations happen during the summer (warmer) months (see Figs. 2b and 8) in correspondence with the strongest $\mathrm{t} 2$ bias (see Figs. $3 \mathrm{a}$ and $\mathrm{S} 4$ ). This seems to indicate that the main limitations of current generation GCMs in terms of air temperature for the Mediterranean region are happening during the warmer period of the year. However, the fact that for CCLM-ERAin also the largest biases happen during the summer months indicates that the RCM is also contributing (although in smaller amount) to the observed temperature underestimation.

Cloud cover is typically overestimated by both CCLM realizations (Fig. 4) as also shown by Figs S5 and S6 (left column). The bias correction reduces overall tcc (right column Fig. 4), but it could be seen in Fig. S4 that, even after bias-correction, summer tcc is still overestimated by the models especially in the NW Mediterranean region, while it is slightly underestimated in the eastern basin. This is not in agreement with reported values from models within the CIRCE initiative (Dubois et al. 2012) as they typically show an underestimation of tcc values. However, also in this previous work, MPI was reported to show a consistent overestimation of tcc during summer months. In our analysis, CCLM-MPI realization is the one showing the largest tcc overestimation for both winter and summer months (Figs. S3 and S4).

Also strong deviations are observed in both GCMs realization for wind intensity (Fig. 5), with the mean ratio data/ model being 0.59-1.2 (U-V) for CCLM-MPI and 0.82-1.1 (U-V) for CCLM-EC (Table 5). From these ratios it is clear that the $\mathrm{U}$ component of the wind is the value being mostly overestimated by the GCMs-driven realizations. In the spatial seasonal maps of wind intensity (Figs. S1 and S2) it could be seen that winter winds are reasonably well reproduced after the bias correction although for CCLMMPI and CCLM-EC there is an underestimation of wind intensity over the Aegean and eastern Mediterranean (Fig. 
S1). For summer, on the other hand, both realizations tend to overestimate winds in the NW Mediterranean (Fig. S2) even after the bias correction.

Clearly, SST simulated in the CCLM-MPI and CCLMEC driven simulations improved after applying the biascorrection to the atmospheric variables. Both mean deviation (Table 2) and the percentage of the basin within the observational error (Figs. 6, 7, 8) are much better than when using the uncorrected variables. The effect is much less noticeable for the surface currents distributions (Fig. 9e, g) although the $\mathrm{BC}$ jet seems to behave in a slightly better way for the corrected CCLM-MPI realization (Fig. 9e).

What is greatly affected by the bias-correction in these two simulations is the position and extension of winter deep convection zones (Fig. 12e, g). Deep MLD are restricted to their expected regions (Gulf of Lion, Crete and southern Adriatic) (e.g., Beuvier et al. 2010) after the bias-correction, while also mean and maximum winter MLD are much closer to the ones obtained from the ERAin forced simulation (Fig. 12a). This comparison on winter mixed layer is indicating that the bias-correction process here applied is not only changing the surface characteristics of the simulated ocean but also serve to improve the representation of the vertical stratification in the Mediterranean basin.

From the spatial analysis of uncorrected/corrected atmospheric variables commented in the previous paragraphs (see maps in supplementary information) it seems that the most problematic area for climate models within the Mediterranean Sea is the western/northwestern basin where they tend to underestimate $\mathrm{t} 2$ and overestimate tcc and wind speed. This might be the reason why simulated SSTs in this region are consistently colder than observations using all CCLM realizations (Fig. 6) even after applying the bias correction. This is especially true for summer months (Fig. 8) as winter values are much better simulated (Fig. 7).

\subsection{Evaluating the relative importance of the different atmospheric variables for the surface ocean characteristics}

By analyzing separately the contribution of the different variables to the correction in the simulated SST we have been able to identify the wind as the most important atmospheric forcing to be corrected. This holds true for two of the three realizations of the RCM, the one using ERAin data as boundary conditions and the one using MPI model (Figs. 10, 11a). For the third realization (CCLM-EC) the results are somehow different as here the wind correction has a comparable effect as the one from temperature and cloud cover correction. This could be related to the larger deviation $\mathrm{t} 2$ has for this particular realization with respect to ERAin data (e.g., Figs. 3, S3 and S4).

However, because of the different correction method applied to winds, its relative importance on the simulated ocean properties could be questioned. Henceforth we performed a new set of corrections on $\mathrm{t} 2$ and tcc from CCLMMPI and CCLM-EC using the same approach as for wind (i.e., the baseline shift). The ocean model was run using these newly corrected variables and simulated SST were compared with the ones obtained using the previous correction (orange lines in Fig. 11a, b). The root-mean-square deviation (RMSD) between simulated SSTs with the two correction methods is $0.09{ }^{\circ} \mathrm{C}$ for CCLM-MPI and $0.05{ }^{\circ} \mathrm{C}$ for CCLM-EC. These tiny differences indicate that the used bias correction method is not fundamental for the obtained results and further strengthens our finding on the paramount importance of wind correction for Mediterranean Sea modelling.

\section{Conclusions}

In conclusion, we have shown that a relatively simple, spatially-uniform bias correction methodology could help to improve simulated surface oceanic conditions of the Mediterranean basin when forcing an ocean model with atmospheric variables downscaled from RCM realizations. Our detailed analysis has also shown that, typically, wind intensity is the most important variable to be corrected in order to obtain reasonable surface ocean conditions, with most realizations showing an overestimation of the meridional component of the wind vector, while zonal intensity is typically underestimated. Given its large importance for ocean simulations, improved and more abundant wind observations over the sea are desirable together with a better representation of its dynamics in regional climate models. Finally, our results seem to point out the lateral boundary conditions used to force the RCM as the main origin of detected bias, with the downscaling performed by CCLM introducing smaller deviations. By achieving in this way a realistic simulation of present day surface characteristics of the hydrodynamic system, we might be able to analyze current and future biogeochemical conditions of the studied basin using the atmospheric scenarios provided by CCLM although the stability of the deeper water layers remains an open issue to be solved for this particular ocean model setup.

Acknowledgments We acknowledge the World Climate Research Programme's Working Group on Coupled Modelling, which is responsible for CMIP, and we thank the climate modeling groups for producing and making available their model output. For CMIP the U.S. Department of Energy's Program for Climate Model Diagnosis and Intercomparison provides coordinating support and led 
development of software infrastructure in partnership with the Global Organization for Earth System Science Portals. This contribution is part of the MedCordex initiative and the HyMex program.

Open Access This article is distributed under the terms of the Creative Commons Attribution 4.0 International License (http://creativecommons.org/licenses/by/4.0/), which permits unrestricted use, distribution, and reproduction in any medium, provided you give appropriate credit to the original author(s) and the source, provide a link to the Creative Commons license, and indicate if changes were made.

\section{References}

Adani M, Dobricic S, Pinardi N (2011) Quality assessment of a 1985-2007 Mediterranean Sea reanalysis. J Atmos Ocean Tech 28:569-589. doi:10.1175/2010JTECHO798.1

Adloff F, Somot S, Sevault F, Jorda G, Aznar R, Deque M, Herrmann M, Marcos M, Dubois C, Padorno E, Alvarez-Fanjul E, Gomis D (2015) Mediterranean Sea responses to climate change in an ensemble of twenty first century scenarios. Clim Dyn 45(9):2775-2802. doi:10.1007/s00382-015-2507-3

Artegiani A, Bregant D, Paschini E, Pinardi N, Raicich F, Russo A (1997) The Adriatic Sea general circulation, Part I airsea interactions and water mass structure. J Phys Oceanogr 27:1492-1514

Beuvier J, Sevault F, Herrmann M, Kontoyiannis H, Ludwig W, Rixen M, Stanev E, Béranger K, Somot S (2010) Modeling the Mediterranean Sea interannual variability during 1961-2000: focus on the Eastern Mediterranean Transient. J Geophys Res 115:C08017. doi:10.1029/2009JC005950

Boberg F, Christensen JH (2012) Overstimation of Mediterranean summer temperature projections due to model deficiencies. Nat Clim Chang 2:433-436. doi:10.1038/NCLIMATE1454

Burchard H, Bolding K (2002) GETM, a general estuarine transport model. European Commission, Ispra

Castellon A, Font J, Garcia-Ladona E (1990) The Liguro-Provenc, alCatalan current (NW Mediterranean) observed by Doppler profiling in the Balearic Sea. Scientia Marina 54:269-276

Coll M, Cury P, Azzurro E, Bariche M, Bayadas G, Bellido JM, Chaboud C, Claudet J, El-Sayed AF, Gascuel D, Knittweis L, Pipitone C, Samuel-Rhoads Y, Taleb S, Tudela S, Valls A (2013) The scientific strategy needed to promote a regional ecosystem-based approach to fisheries in the Mediterranean and Black Sea. Rev Fish Biol Fish 23:415-434

D’Ortenzio F, Iudicone D, de Boyer Montegut C, Testor P, Antoine D, Marullo S, Santoleri R, Madec G (2005) Seasonal variability of the mixed layer depth in the Mediterranean Sea as derived from in situ profiles. Geophys Res Lett 32:L12605. doi:10.1029/200 5GL022463

Davies HC (1976) A lateral boundary formulation for multi-level prediction models. Q J R Meteorol Soc 102(432):405-418. doi:10.1002/qj.49710243210

Davies HC (1983) Limitations of some common lateral boundary schemes used in regional NWP models. Mon Weather Rev 111:1002-1012. doi:10.1175/1520-0493

Dee DP, Uppala SM, Simmons AJ, Berrisford P, Poli P, Kobayashi S, Andrae U, Balmaseda MA, Balsamo G, Bauer P, Bechtold P, Beljaars ACM, van de Berg L, Bidlot J, Bormann N, Delsol C, Dragani R, Fuentes M, Geer AJ, Haimberger L, Healy SB, Hersbach H, Holm EV, Isaksen L, Kallberg P, Kohler M, Matricardi M, McNally AP, Monge-Sanz BM, Morcrette JJ, Park BK, Peubey C, de Rosnay P, Tavolato C, Thepaut JM, Vitart F (2011) The
ERA-Interim reanalysis: configuration and performance of the data assimilation system. Q J R Meteorol Soc 137:553-597

Dell' Aquila A, Calamanti S, Ruti P, Struglia MV, Pisacane G, Carillo A, Sannino G (2012) Impacts of seasonal cycle fluctuations in an A1B scenario over the Euro-Mediterranean. Clim Res 52:135157. doi: $10.3354 / \mathrm{cr} 01037$

Doms G (2011) A description of the nonhydrostatic regional COSMO model part 1: dynamics and numerics. DWD, Offenbach, Germany. http://www.cosmo-model.org/content/model/documentation/core/default.htm

Dosio A, Panitz HJ (2015) Climate change projections for CORDEXAfrica with COSMO-CLM regional climate model and differences with the driving global climate. Clim Dyn. doi:10.1007/ s00382-015-2664-4

Dosio A, Paruolo P (2011) Bias correction of the ENSEMBLES highresolution climate change projections for use by impact models: evaluation on the present climate. J Geophys Res 116:D161106

Dosio A, Paruolo P, Rojas R (2012) Bias correction of the ENSEMBLES high resolution climate change projections for use by impact models: analysis of the climate change signal. J Geophys Res 117:D171110

Dosio A, Panitz HJ, Schubert-Frisius M, Luethi D (2015) Dynamical downscaling of CMIP5 global circulation models over CORDEX-Africa with COSMO-CLM: evaluation over the present climate and analysis of the added value. Clim Dyn 44:2637-2661. doi:10.1007/s00382-014-2262-x

Dubois C, Somot S, Calmanti S, Carillo A, Déqué M, Dell'Aquilla A, Elizalde A, Gualdi S, Jacob D, L'Hévéder B, Li L, Oddo P, Sannino G, Scoccimarro E, Sevault F (2012) Future projections of the surface heat and water budgets of the Mediterranean Sea in an ensemble of coupled atmosphere-ocean regional climate models. Clim Dyn 39:1859-1884

Ehret U, Zehe E, Wulfmeyer V, Warrach-Sagi K, Liebert J (2012) Should we apply bias correction to global and regional climate model data? Hydr Earth Syst Sci 16:3391-3404. doi:10.5194/ hess-16-3391-2012

Garcia-Sotillo M, Ratsimandresy A, Carretero J, Bentamy A, Valero F, Gonzalez-Rouco F (2005) A high-resolution 44-year atmospheric hindcast for the Mediterranean basin: contribution to the regional improvement of global reanalysis. Clim Dyn 25:219 236. doi:10.1007/s00382-005-0030-7

Heinrich G, Gobiet A (2011) The future of dry and wet spells in Europe: a comprehensive study based on the ENSEMBLES regional climate models. Int J Clim 32:1951-1970. doi:10.1002/joc.2421

Heise E, Lange M, Ritter B, Schrodin R (2003) Improvement and validation of the multilayer soil model. COSMO News1 3:198-203

Houpert L, Testor P, Durrieu de Madron X, Somot S, D’Ortenzio F, Estournel C, Lavigne H (2015) Seasonal cycle fo the mixed layer, the seasonal thermocline and the upper-ocean heat storage rate in the Mediterranean Sea derived from observations. Prog Ocean 132:333-352. doi:10.1016/j.pocean.2014.11.004

Jacob D, Petersen J, Eggert B, Alias A, Bossing Christensen O, Bouwer LM, Braun A, Colette A, Deque M, Georgievski G, Georgopoulou E, Gobiet A, Menut L, Nikulin G, Haensler A, Hempelmann N, Jones C, Keuler K, Kovats S, Kroner N, Kotlarski S, Kriegsmann A, Martin E, van Meijgaard E, Moseley C, Pfeifer S, Preuschmann S, Radermacher C, Radtke K, Rechid D, Rounsevell M, Samuelsson P, Somot S, Soussana J-F, Teichmann C, Valentini R, Vautard R, Weber B, Yiou P (2014) EURO-CORDEX: new high-resolution climate change projections for European impact research. Reg Environ Chan 14(2):563-578. doi:10.1007/ s10113-013-0499-2

Josey SA (2003) Changes in heat and freshwater forcing of the eastern Mediterranean and their influence on deep water formation. $\mathrm{J}$ Geophys Res 108:3237. doi:10.1029/2003JC001778 
Kondo J (1975) Air-sea bulk transfer coefficients in diabatic conditions. Bound Lay Met 9:91-112

Kotlarski S, Keuler K, Christensen OB, Colette A, Deque M, Gobiet A, Goergen K, Jacob D, Luthi D, van Meijgaard E, Nikulin G, Schar C, Teichmann C, Vautard R, Warrach-Sagi K, Wulfmeyer V (2014) Regional climate modeling on European scales: a joint standard evaluation of the EURO-CORDEX RCM ensemble. Geosci Model Dev 7:1297-1333. doi:10.5194/gmd-7-1297-2014

Lascaratos A, Williams R, Tragou E (1993) A mixed-layer study of the formation of Levantine intermediate water. J Geophys Res 98:14739-14749

Li H, Sheffield J, Wood EF (2010) Bias correction of monthly precipitation and temperature fields from intergovernmental panel on climate change AR4 models using equidistintant quantile matching. J Geophys Res 115:D10101. doi:10.1029/2009JD012882

Llasses J, Jordà G, Gomis D, Adloff F, Macías D, Harzallah A, Arsouze T, Akthar N, Li L, Elizalde A, Sannino G (submitted) Heat and salt redistribution in the Mediterranean Sea in the MedCORDEX model ensemble. Clim Dyn this issue

Lott F, Miller MJ (1997) A new subgrid-scale orographic drag parametrization: its formulation and testing. Q J R Meteorol Soc 123(537):101-127. doi:10.1002/qj.49712353704

Macias D, García-Gorríz E, Stips A (2013) Understanding the causes of recent warming of Mediterranean waters. How much could be attributed to climate change? PLoS One 8:e81591

Macías D, Stips A, Garcia-Gorriz E (2014a) The relevance of deep chlorophyll maximum in the open Mediterranean Sea evaluated through 3D hydrodynamic-biogeochemical coupled simulations. Ecol Model 281:26-37

Macías D, García-Gorríz E, Piroddi C, Stips A (2014b) Biogeochemical control of marine productivity in the Mediterranean Sea during the last 50 years. Glob Biochem Cyc 28:897-907. doi:10.1002/2014 GBC004846

Maraun D, Wetterhall F, Ireson AM, Chandler RE, Kendon EJ, Widmann M, Brienen S, Rust HW, Sauter T, Themessl M, Venema VKC, Chun KP, Goodess CM, Jones RG, Onof C, Vrac M, Thiele-Eich I (2010) Precipitation downscaling under climate change: Recent developments to bridge the gap between dynamical models and the end user. Rev Geophys. doi:10.1029/200 9rg000314

Marullo S, Nardelli BB, Guarracino M, Santorelli R (2007) Observing the Mediterranean Sea from space: 21 years of PathfinderAVHRR sea surface temperatures (1895 to 2005): re-analysis and validation. Ocean Sci 3:299-310

Mellor GL, Yamada T (1982) Development of a turbulence closure model for geophysical fluid problems. Rev Geophys 20(4):851875. doi:10.1029/RG020i004p00851

Millot C, Taupier-Letage I (2005) Circulation in the Mediterranean Sea. Hdb Env Chem 5:29-66. doi:10.1007/b107143

Mironov D, Raschendorfer M, (2001) Evaluation of empirical parameters of the new LM surface-layer parameterization scheme: results from numerical experiments including soil moisture analysis. COSMO technical report 1, DWD, Offenbach, Germany

Nykjaer L (2009) Mediterranean Sea surface warming 1985-2006. Clim Res 39:11-17

Oguz T, Macias D, Tintore J (2014) Fueling phytoplankton production by a meandering frontal jet: a case study for the Alboran Sea (Western Mediterranean). PLoS One 9:e111482. doi:10.1371/ journal.pone. 0111482

Oguz T, Macias D, Tintore J (2015) Ageostrophic frontal processes controlling phytoplankton production in the Catalano-Balearic Sea (Western Mediterranean). PLoS One 10(6):e0129045. doi:10.1371/journal.pone.0129045

Panitz HJ, Dosio A, Buechner M, Luethi D, Keuler K (2014) COSMO-CLM (CCLM) climate simulations over CORDEX Africa domain: analysis of the ERA-Interim driven simulations at 0.44 and 0.22 resolution. Clim Dyn 42:30153038. doi:10.1007/s00382-013-1834-5

Paulson CA, Simpson JJ (1977) Irradiance measurements in the upper ocean. J Phys Oceanogr 7:952-956

Payne RE (1972) Albedo of the sea surface. J Atmos Sci 29:959-970

Pettenuzzo D, Large WG, Pinardi N (2010) On the corrections of ERA 40 surface flux products consistent with the Mediterranean heat and water budgets and the connection between basin surface total heat flux and NAO. J Geophys Res 115:C06022

Piani C, Weedon GP, Best M, Gomes SM, Viterbo P, Hagemann S, Haerter JO (2010) Statistical bias correction of global simulated daily precipitation and temperature for the application of hydrological models. J Hydrol 39:199-215. doi:10.1016/j. hydrol.2010.10024

Raschendorfer M (2001) The new turbulence parameterization of LM.COSMO Newsl 1:90-98

Reed RK (1977) On estimating insolation over the ocean. J Phys Oceanogr 7:781-800

Ritter B, Geleyn JF (1992) A comprehensive radiation scheme for numerical weather prediction models with potential applications in climate simulations. Mon Weather Rev 120(2):303-325

Salat J (1995) The interaction between the Catalan and Balearic currents in the southern Catalan Sea. Oceanol Acta 18:227-234

Sanchez-Gomez E, Somot S, Josey SA, Dubois C, Elguindi N, Déqué M (2011) Evaluation of Mediterranean Sea water and heat budgets simulated by an ensemble of high resolution regional climate models. Clim Dyn 37:2067-2086

Sannino G, Carillo A, Pisacane G, Naranjo C (2015) On the relevance of tidal forcing in modelling the Mediterranean thermohaline circulation. Prog Oceanogr 134:304-329

Schott F, Visbeck M, Send U, Fisher J, Stramma L, Desaubies Y (1996) Observations of deep convection in the Gulf of Lions, northern Mediterranean, during the winter of 1991/1992. J Phys Oceanogr 26:505-524

Schrodin R, Heise E (2002) A new multi-layer soil-model. COSMO Newsl 2:139-151

Schulz JP (2008) Introducing sub-grid scale orographic effects in the COSMO model. COSMO Newsl 9:29-36

Seifert A, Beheng KD (2001) A double-moment parameterization for simulating autoconversion, accretion and self-collection. Atmos Res 59-60:265-281

Siokou-Frangou I, Christaki U, Mazzocchi MG, Montresor M, Ribera d'Alcal M, Vaque D, Zingone A (2010) Plankton in the open Mediterranean Sea: a review. Biogeosciences 7:1543-1586. doi:10.5194/bg-7-1543-2010

Somot S, Sevault F, Deque M (2006) Transient climate change scenario simulation of the Mediterranean Sea for the twenty-first century using a high-resolution ocean circulation model. Clim Dyn 27:851-879

Steinacher M, Joos F, Frölicher TL, Bopp L, Cadule P, Cocco V, Doney SC, Gehlen M, Lindsay K, Moore JK, Schneider B, Segschneider J (2010) Projected 21st century decrease in marine productivity: a multi-model analysis. Biogeosciences 7:979-1005

Stips A, Bolding K, Pohlman T, Burchard H (2004) Simulating the temporal and spatial dynamics of the North Sea using the new model GETM (general estuarine transport model). Oce Dyn $54: 266-283$

Tiedtke M (1989) A comprehensive mass flux scheme for cumulus parameterization in large-scale models. Mon Weather Rev 117(8):1779-1800

Uppala SM, Dee DP, Kobayashi S, Berrisford P, Simmons AJ (2008) Towards a climate data assimilation system: status update of ERA-Interim. ECMWF Newsletter 115:12-18

Vautard R, Gobiet A, Jacob D, Belda M, Colette A, Deque M, Fernandez J, Garcia-Diez M, Goergen K, Guttler I, Halenka T, 
Karacostas T, Katragkou E, Patarcic M, Scinocca J, Sobolowski S, Suklitsch M, Teichmann C, Warrach-Sagi K, Wulfmeyer V, Yiou P (2013) The simulation of European heat waves from an ensemble of regional climate models within the EUROCORDEX project. Clim Dyn 41:2555-2575. doi:10.1007/ s00382-013-1714-z

Vichi M, May W, Navarra A (2003) Response of a complex ecosystem model of the northern Adriatic Sea to a regional climate change scenario. Clim Res 24:141-158
Wicker LJ, Skamarock WC (2002) Time-splitting methods for elastic models using forward time schemes. Mon Weather Rev 130(8):2088-2097. doi:10.1175/1520-0493(2002)

Wood AW, Leung LR, Sridhar V, Lettenmaier DP (2004) Hydrologic implications of dynamical and statistical approaches to donwscaling climate model outputs. Clim Change 62:189-216. doi:10.1023/B:CLIM.0000013685.99609.9e 